
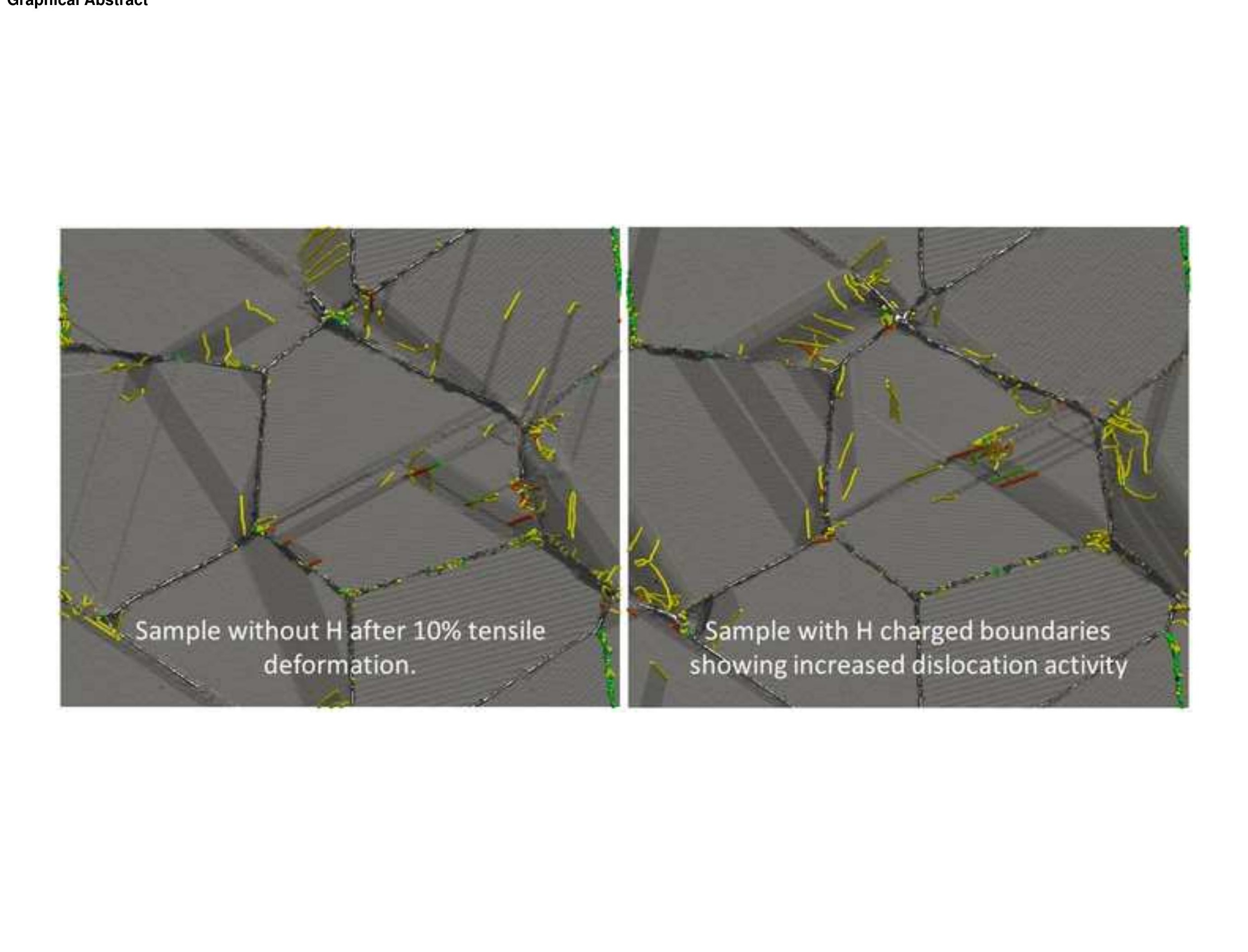

Sample without $\mathrm{H}$ after $10 \%$ tensile deformation. showing increased dislocation activity

Graphical Abs

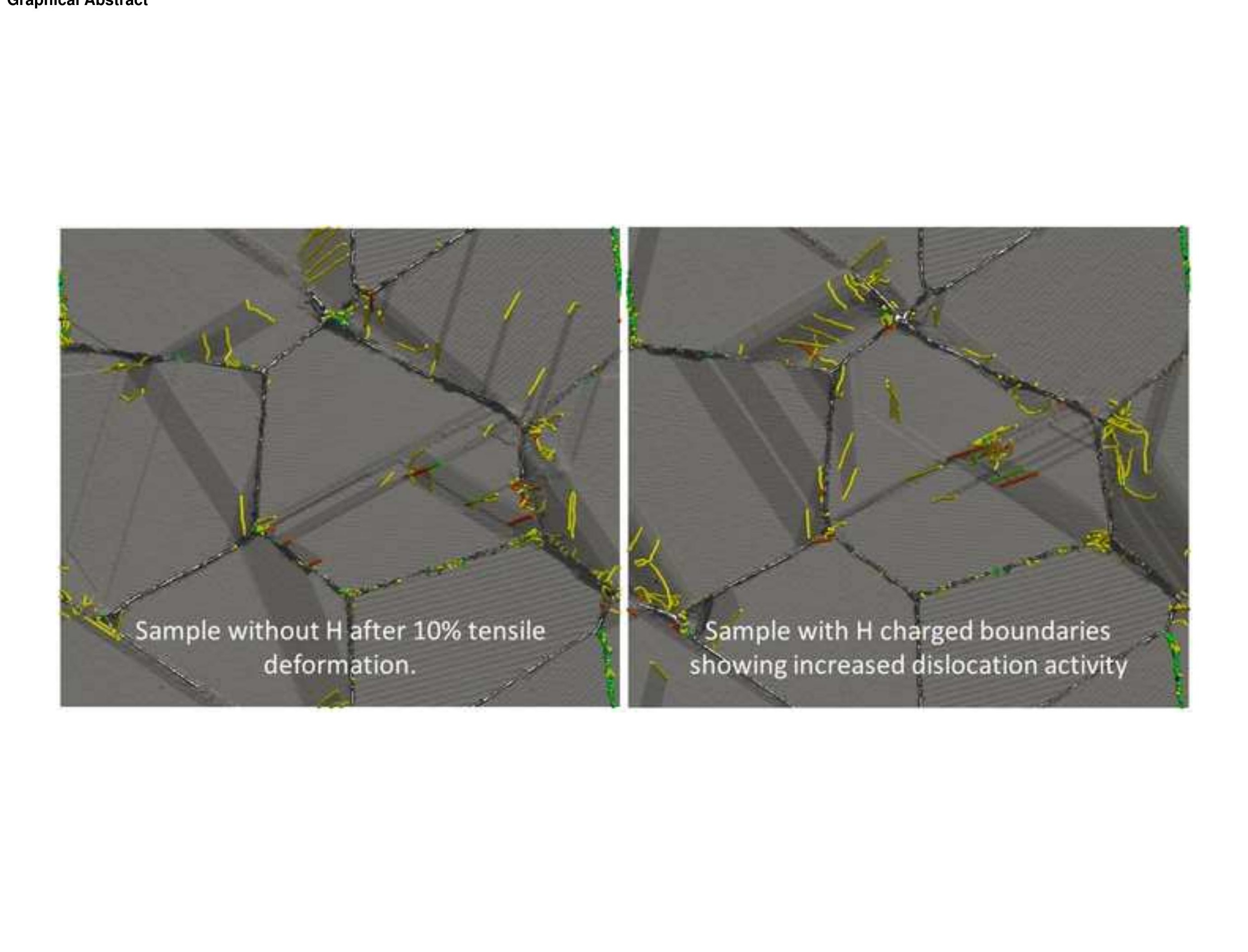

.
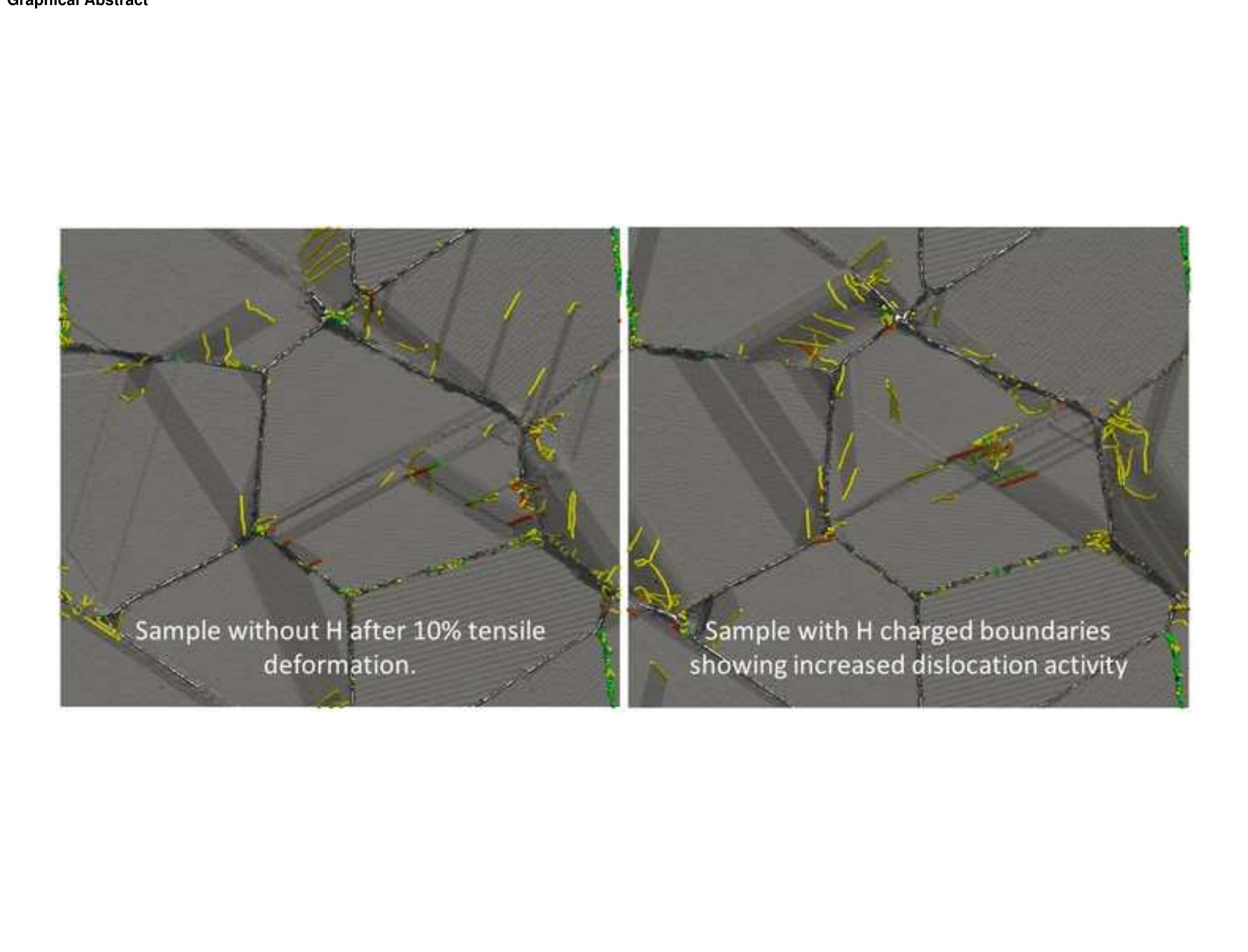


\title{
Atomistic Studies of Hydrogen Effects on Grain Boundary Structure and Deformation Response in FCC Ni
}

\author{
BRYAN KUHR ${ }^{1}$, DIANA FARKAS ${ }^{1}$ AND IAN M. ROBERTSON²34 \\ ${ }^{1}$ Department of Materials Science and Engineering, Virginia Polytechnic Institute and State \\ University, Blacksburg, VA 24061 \\ 2Department of Materials Science and Engineering, University of Wisconsin, Madison, WI \\ 53706 \\ ${ }^{3}$ Department of Engineering Physics, University of Wisconsin, Madison, WI 53706 \\ ${ }^{4}$ International Institute for Carbon-Neutral Energy Research (WPI-I2CNER), Kyushu \\ University, 744 Motooka, Nishi-ku, Fukuoka, Fukuoka 819-0395, Japan
}

Corresponding author:

Bryan Kuhr

(517)290-0193

kuhrbrya@vt.edu

213 Holden Hall

445 Old Turner Street

Blacksburg, VA 24061

\begin{abstract}
The effect of hydrogen in the grain boundary on the mechanical response of random microstructures was studied by using atomistic simulation techniques and model interatomic potentials. The model interatomic potentials mimic properties of interstitial $\mathrm{H}$ in fcc materials within the limitations of empirical force laws. We report fully three-dimensional atomistic molecular dynamics studies of the mechanical response of identical samples with and without $\mathrm{H}$ in the grain boundaries. $\mathrm{H}$ content changes the structure of the grain boundaries and plays a critical role in the emission of dislocations from the grain boundaries under an applied stress. For lower deformation levels, the presence of $\mathrm{H}$ increased the yield strength of the samples, whereas for higher deformation levels, it increased dislocation emission from grain boundary sources, resulting in an increase in the number of dislocations in pile-ups at the grain boundaries. Increasing the $\mathrm{H}$ content resulted in increasingly larger cracks being formed on the grain boundaries, consistent with decreased grain boundary cohesion. Our results support a picture of hydrogen embrittlement resulting from the combined effects of hydrogen on plasticity as well as grain boundary decohesion.
\end{abstract}

KEYWORDS: Hydrogen embrittlement, Mechanical Properties, Molecular Dynamics, Plasticity, Nickel 

proposed to account for it $[1,2]$. One manifestation of hydrogen-induced failure is that in some systems it can result in a transition in the failure mode from ductile transgranular to intergranular. Until recently this transition was interpreted as being driven by hydrogen segregated to the grain boundary reducing the cohesive strength of the grain boundary such that it became the weakest link in the system [3-5]. Here it was noted that there was evidence for plasticity but the role, if any, of it in the hydrogen-induced intergranular failure was not ascertained. However, recent experimental observations of the microstructure associated with hydrogen-induced intergranular failure in $\mathrm{Ni}$ [6] and Fe [7] have suggested that although the hydrogen-induced reduction in the cohesive strength is ultimately the cause of the failure, the conditions for establishing this failure mode are driven by hydrogen-enhanced plasticity processes. These include the ensuing changes in the grain boundary structure and in hydrogen content associated with slip transfer across it as well as the increase in the local stress state around the grain boundary due to the hydrogenaccelerated plasticity that occurs prior to the initiation of an intergranular crack [8].

However, full understanding of the hydrogen-induced failure mechanisms requires studies at the atomistic scale that are very difficult experimentally. Computer simulation techniques have been used for several decades now to investigate the mechanical response of nano-crystalline materials [9-13]. In these materials, grain boundaries contribute to the deformation process through the emission and/or absorption of Shockley partial dislocations. Additional mechanisms of accommodation of the stress at the grain boundaries have been uncovered, such as grain boundary sliding and strain-driven grain boundary migration. 
For example, Sansoz and Molinari performed a series of quasi-continuum simulations at OK of a grain boundary, GB, in nano-sized $\mathrm{Cu}$ and $\mathrm{Al}$ bicrystals deformed under shear [14]. They emphasized that despite the importance of the GB structure for intergranular and intragranular deformation in nanocrystalline metals, the relation between the GB structure and their mechanical response is not well understood [15]. An important role of atomistic simulations is to inform the development of large-scale models of the behaviour of the interface between crystals [16]. Cao and Wei [17] performed large scale MD simulations of pure nanocrystalline, $\mathrm{nc}, \mathrm{Ni}$, subjected to uniaxial tensile loading and observed that the strain is mainly localized at GBs, with GB plasticity being a major contribution to the overall plastic deformation. Vo et al. [18] performed MD simulations of tensile tests at different strain rates for polycrystalline $\mathrm{Cu}$ with grain sizes in the range of $5-20 \mathrm{~nm}$. The contributions to plastic deformation due to dislocation activity and GB sliding were quantified. They found that dislocation activity increased with grain size but decreased with increasing strain rates. These examples are part of a large body of literature that has studied the connections between grain boundaries and microstructure and mechanical behaviour in pure fcc materials with general grain boundaries [19].

In parallel efforts, simulations have been utilized to understand the influence of $\mathrm{H}$ on the mechanical response of materials [20-27]. These studies have addressed $\mathrm{H}$ interstitials in bulk fcc materials [28, 29] and bicrystals [30]. The embrittling and strengthening effects of hydrogen, boron, and phosphorus on a $\Sigma=5$ (210) [100] nickel grain boundary were investigated by means of the full-potential linearized augmented plane-wave method [31]. Hickel et al. aimed at understanding segregation and diffusion mechanisms of $\mathrm{H}$ in steels using ab initio methods and discussed the advantages and shortcomings of the technique [32]. Furthermore, there have been 
significant efforts to model hydrogen embrittlement using continuum approaches and multi-scale methods [33-38] .

The current state of knowledge postulates that in the case of hydrogen-induced intergranular failure, hydrogen located at the grain boundary lowers the grain boundary cohesive energy but there is also strong experimental evidence that $\mathrm{H}$ significantly affects the plastic response of the material [8]. Through in-situ straining experiments in a controlled environment transmission electron microscope it has been shown that $\mathrm{H}$ increases the dislocation mobility, the dislocation generation rate and decreases the separation distance between dislocations in a pileup against an obstacle such as a grain boundary; this work is summarized and reviewed by Robertson et al [39]. Interestingly, the effect on the behavior of dislocations was ubiquitous, occurring in pure fcc, bcc and hcp metals as well as alloys based on them. Hydrogen-enhanced plasticity has been used to explain the response of mechanical property tests designed to assess the activation energy and volume of dislocation slip [40, 41]. The effect on the dislocation mobility was explained by hydrogen attached to a dislocation modifying the stress field of the dislocation such that in some directions the stress field was decreased and in others it was increased - this hydrogen shielding effect is the basis for the hydrogen-enhanced localized plasticity mechanism [33]. Song and Curtin [23, 24, 42] performed atomistic simulations of the effects of $\mathrm{H}$ on edge dislocation mobility and pile-ups in order to investigate possible nanoscale mechanisms for hydrogen-enhanced localized plasticity. In contrast to the experimental findings they found that the Cottrell-like hydrogen atmospheres following the moving dislocations, leads to a resistance to dislocation motion that is consistent with solute drag theory. They also found that these atmospheres do not affect the equilibrium spacing of dislocations in a pile-up, which contradicts experimental observations [39]. Finally, Song and Curtin pointed out that a 
mechanistic understanding of $\mathrm{H}$-enhanced localized plasticity requires the evaluation of more complex H-dislocation interactions [23]. $\mathrm{Li}$ and co-workers utilized multi-scale simulations to study the role of H-vacancy complexes [43]. They performed large-scale molecular dynamics simulations to show that $\mathrm{H}$-vacancy complexes are quite stable and tend to grow in size. Chandler and co-workers [27] performed molecular dynamics (MD) simulations to study hydrogen effects on nano-void nucleation in nickel low-angle and high-angle symmetrical [001] tilt grain boundaries. The results showed that hydrogen atoms were trapped at the grain boundaries and enhanced nano-void nucleation. These simulations could explain the nano-voids observed experimentally in the $\mathrm{H}$ induced failure of $\mathrm{Fe}$ and steels $[44,45]$. Here it is important to note that as the nano-void features were confined to the fracture surface and not observed subsurface, an alternate explanation for the formation of these surface features has been put forth [46].

The present work constitutes a study of fully 3D samples containing randomly generated grain boundaries, created with and without various levels of intergranular $\mathrm{H}$ impurities. As the timescale of the simulations cannot account for lattice diffusion of hydrogen or hydrogen transport by the mobile dislocations, this study considered only the effect of hydrogen on the grain boundary structure and the emission of dislocations from it. The grain boundaries in the digital samples are random boundaries and the study focuses on the response of the polycrystal to an applied tensile deformation in a strain-controlled virtual tensile test. The results presented in this paper are organized as follows: First, we analyze the effects of $\mathrm{H}$ content on the structure of these random grain boundaries. The effect of hydrogen removal from the grain boundary by the emitted dislocations is not considered, the hydrogen concentration on the grain boundary is kept constant. Next, we discuss the effect of the intergranular $\mathrm{H}$ on the emission of dislocations 
from grain boundaries and the resulting dislocation pile ups at the boundaries. Finally, we present our results on the effect of the $\mathrm{H}$ in the grain boundary on the nucleation and propagation of intergranular cracks in these polycrystalline microstructures.

\section{SIMULATION PROCEDURE}

\subsection{Interatomic potentials}

The deformation behavior under tension was modeled using molecular dynamics and embedded atom (EAM) interatomic potentials [47] developed for dilute interstitial $\mathrm{H}$ impurities [29]. These potentials are used as model potentials and are subject to the limitations of empirical potentials and, in particular, the central nature of the Embedded Atom Method [48]. The particular potentials used here were developed based on the heat and volume of solution of $\mathrm{H}$ in $\mathrm{Ni}\left(0.18 \mathrm{eV}\right.$ and $\left.0.0023 \mathrm{~nm}^{3}\right)$ [29]. The migration energy of $\mathrm{H}$ in the $\mathrm{Ni}$ lattice given by the potential is $0.35 \mathrm{eV}$. These values are very similar to those given by the potential of Baskes and co-authors [48]. In the potentials used here, $\mathrm{Ni}$ is represented by the potential of Voter and Chen [49]. The potentials selected reproduce in a simple way the length and strength of the H-Ni bond. They therefore crudely capture the basic size effects of the interaction of $\mathrm{H}$ with the fcc host material as well as the magnitude of the chemical interaction. We note that the potentials are appropriate for low $\mathrm{H}$ concentrations only [50]. As mentioned above, our results are subject to the general limitations intrinsic to empirical potentials, and are indicative of trends only.

\subsection{Sample generation and relaxation}

The digital samples studied here have a polycrystalline thin-film configuration with randomly oriented grain boundaries. All samples were created using a Voronoi tessellation 
method [19]. The samples contain 6 grains (see Figure 1) with an average size of $40 \mathrm{~nm}$ [51]. For reference purposes the grains are identified numerically in each of the figures. This grain size, chosen to avoid nano-size effects, is still too small to support Frank-Read dislocation sources and dislocation multiplication. Therefore, the dislocations observed are generated from grain boundary dislocation sources. Each sample contained roughly 10 million atoms and had a thickness of about $8 \mathrm{~nm}$. The samples are periodic in the $\mathrm{x}$ - and $\mathrm{y}$-directions with free surfaces in the z-direction.

The grain centers and orientations were chosen at random and the resulting grain boundaries are all high-angle random boundaries, except for the boundary between grains 4 and 6, which was close to a $\Sigma=3$ misorientation. Grain boundary relaxation was achieved using molecular dynamics [52] in the LAMMPS implementation [53] by increasing the temperature to $700 \mathrm{~K}$ for $50 \mathrm{ps}$ and then returning to $300 \mathrm{~K}$ for $50 \mathrm{ps}$. An atom was determined to be a boundary atom if its centro-symmetry parameter was above 3 and it was $1 \mathrm{~nm}$ away from the sample surface [54]. In order to determine the dependence of intergranular failure on the hydrogen coverage on grain boundaries, the hydrogen coverage, expressed as $\mathrm{H}$ atoms per $\mathrm{nm}^{2}\left(\mathrm{H} / \mathrm{nm}^{2}\right)$ of grain boundary, was varied up to $8 \mathrm{H} / \mathrm{nm}^{2}$. Our maximum hydrogen coverage level corresponds to approximately half of a monolayer. All grain boundaries in the system had roughly the same level of hydrogen coverage. The hydrogen atoms were positioned adjacent to grain boundary atoms, and the system allowed to relax for $34.5 \mathrm{ps}$ at $300 \mathrm{~K}$.

\subsection{Virtual tensile testing}

After relaxation, all samples underwent virtual strain-controlled tensile deformation at $300 \mathrm{~K}$ and a strain rate of $3 \times 10^{8} / \mathrm{s}$. The LAMMPS code [53] was used for this part of the work, 
with a Nose-Hoover barostat and thermostat. Periodicity in the direction of the tensile axis was used to control the deformation level while pressure was maintained at zero in the direction perpendicular to it. The tensile axis was chosen to be in the horizontal direction in Figure 1. It is appreciated that the strain rate used in the simulations is several orders of magnitude higher than those used in experiments. This is an intrinsic limitation of the technique. However, it will be shown that for the same simulation parameters, the presence of hydrogen on the grain boundaries influences the response of the system and the differences have parallels to experimental observations of the hydrogen-induced transition from transgranular to intergranular failure. Specifically, this effort addresses the impact of hydrogen on the basic processes of dislocation emission from grain boundaries as well as crack nucleation and propagation along grain boundaries.

\subsection{Analysis and visualization}

Visualization of the results was achieved by tracking the centro-symmetry [54] parameter of each atom as deformation proceeded. Detailed visualization of results is achieved by color coding according to this parameter at each stage of deformation and utilizing Ovito [55]. The dislocation extraction algorithm (DXA) written by Alexander Stukovski [56] was used to detect and characterize dislocations in our samples. This algorithm was run at $0.5 \%$ strain increments. Representations of these dislocations in the sample were generated by color coding the observed dislocations by Burgers vector against the back surface of the sample using the Paraview visualization suite [57]. These dislocations were sorted by Burgers vector and line length, and counted to calculate dislocation density evolution during straining. 


\subsection{Structure of grain boundaries with segregated hydrogen}

During the relaxation of the randomly distributed hydrogen atoms in the grain boundary, the hydrogen atoms diffused along the grain boundary to occupy low energy sites. The presence of $\mathrm{H}$ in the grain boundaries resulted in significant changes in the atomic structure of the grain boundary. The differences are shown in Figure 2 for the grain boundary between grains 1 and 5. The atoms are colored according to their centro-symmetry parameter, except for the $\mathrm{H}$ atoms which are colored black. With increasing hydrogen coverage more grain boundary atoms have higher centro-symmetry parameters (>10) (colored red) as well as larger distorted environments. This result suggests that the impact of hydrogen on the grain boundary cohesive strength has contributions from both compositional as well as structural changes. The compositional effect is well documented and would manifest itself as a reduction of the cohesive strength because of H-bonding effects with $\mathrm{Ni}$. However, it is only recently that the structural component has been recognized as being a contributor [8].

Our results showed that within the times accessible to molecular dynamics the $\mathrm{H}$ that was initially located at the grain boundaries did not diffuse to the bulk, as expected from estimates of the $\mathrm{H}$ diffusivity in bulk $\mathrm{Ni}$. However, our simulation times are indeed enough for $\mathrm{H}$ transport to occur within the grain boundary. This is in agreement with experimental and simulation work showing that grain boundary diffusion of $\mathrm{H}$ in nickel grain boundaries is significantly accelerated from the bulk values [58-63]. Therefore, our structures can represent an equilibrium distribution of $\mathrm{H}$ within the grain boundary but equilibrium with $\mathrm{H}$ in the bulk is not attained.

Some of the $\mathrm{H}$ atoms formed clusters of a few atoms and in association with regions of high free volume within the grain boundary. An example of such a cluster within the grain 
boundary can be seen in Figure 2. Figure 3 shows the distribution of hydrogen in the grain boundary between grains 3 and 4, viewed along the grain boundary plane. After a relaxation time of $35 \mathrm{ps}$, the cluster distribution remained constant with an average cluster size between 1.2 and 2.2 atoms. The average cluster size increased with $\mathrm{H}$ coverage, as shown in Figure 4. The cluster distribution remained stable for relaxation times up to $0.6 \mathrm{~ns}$ at room temperature, confirming that the system has arrived at an equilibrium distribution of $\mathrm{H}$ in random boundaries. Therefore, the relaxation times possible in the molecular dynamics technique allow for sufficient mobility of the $\mathrm{H}$ atoms in the grain boundary to reach this equilibrium at room temperature. The particular location of the $\mathrm{H}$ atoms and clusters depends on the structure of the individual grain boundary at a local level, with disordered large free volume regions preferred for $\mathrm{H}$ occupation.

The frequency distribution of cluster sizes is shown in Figure 5 for the relaxed sample containing $8.0 \mathrm{H}$ atoms $/ \mathrm{nm}^{2}$ in the grain boundaries. We note that even if most of the $\mathrm{H}$ in the grain boundary remains as single atoms or two atom clusters there are a few clusters with up to 6 or $7 \mathrm{H}$ atoms. The fraction of such clusters is quite small but they can have an important impact if they constitute preferred sites for dislocation emission and crack nucleation. The separation distance between $\mathrm{H}$ atoms within the clusters was on average $0.2 \mathrm{~nm}$. This is much larger than the distance between $\mathrm{H}$ atoms in the $\mathrm{H}_{2}$ molecule $(0.074 \mathrm{~nm})$ indicating that the formation of the clusters is driven by the $\mathrm{H}-\mathrm{Ni}$ interaction and not the interaction between $\mathrm{H}$ atoms to form the $\mathrm{H}_{2}$ molecule. The tendency to form clusters of several $\mathrm{H}$ atoms has been discussed for the case of vacancies in $\mathrm{Fe}[43,64]$ and $\mathrm{Ni}[27]$.

Overall, the results of the simulations suggest that increased $\mathrm{H}$ concentrations in the grain boundary produces a more disordered grain boundary structure, with $\mathrm{H}$ atoms clustering in 
regions of high free volume. This is in agreement with simulations by Yu and co-authors [21] who performed a radial distribution function analysis and reported that a high local grain boundary concentration of $\mathrm{H}$ at $900 \mathrm{~K}$ can lead to a more disordered grain boundary.

\subsection{Tensile behavior}

The stress-strain curves for the H-free sample and for samples with different hydrogen coverages on the grain boundary are presented in Figure 6. In all samples, irrespective of hydrogen coverage on the grain boundaries, the stress-strain curves show an upper and lower yield point, which is followed by an increase in stress with the curves falling to a common value. They also show that the $0.2 \%$ offset yield strength increases with hydrogen coverage on the grain boundaries. This increase in yield strength is quantified in Figure 7, which shows the observed values of the yield strength as a function of $\mathrm{H}$ coverage in the grain boundaries. In order to understand this effect of hydrogen on the grain boundary, the changes in the grain boundary structure, dislocation emission and crack nucleation and propagation occurring during the loading were studied. We found that as the emission of dislocations from the grain boundary proceeds, the tendency for clustering of the $\mathrm{H}$ atoms increases. The change in the average cluster size as a function of strain level is compared with that achieved during the simulation time in the system with a grain boundary coverage of $4.8 \mathrm{H} / \mathrm{nm}^{2}$. Only in the presence of strain does the average number of hydrogen atoms in a cluster increase, there is no change with simulation time. This comparison indicates that the cluster sizes was not determined by kinetics and that our relaxation times are adequate. The dependence of the increase in the average cluster size during loading as a function of grain boundary hydrogen coverage is shown in Figure 9. The higher the coverage the greater the increase in the average cluster size. This effect is attributed to 
dislocation emission from the grain boundary creating additional free volume, which permits larger clusters of hydrogen to form.

\subsection{Dislocation emission from the grain boundaries}

Shockley partial dislocations with Burgers vector of the type $<112>/ 6$ were emitted from the grain boundaries and moved across the grain during loading. This is the typical behavior observed in simulations without hydrogen, with regions of high free volume in the grain boundary or triple junctions acting as preferential sites for emission of dislocations [32, 65]. Figure 10a shows an example of the emission of a Shockley partial dislocation from a site on a grain boundary with a high free volume and hydrogen (black atoms); the arrows indicate the direction of dislocation motion. For comparison, the same area is shown in Figure 10b for the sample without hydrogen.

In order to study the qualitative effects of grain boundary hydrogen, the dislocation density was determined as the deformation proceeds for different $\mathrm{H}$ coverage of the grain boundaries. The results are shown in Figure 11. Significant plasticity was observed in all samples. The pure Ni sample has a higher dislocation density at strain levels $\leq 1.5 \%$ as in this range of strain, mobile dislocations exist in pure $\mathrm{Ni}$ only. The generation of dislocations in pure $\mathrm{Ni}$ only is due to the applied stress not exceeding the yield strength of the $\mathrm{H}$ containing materials. With increasing applied stress and at strain levels $\geq 2 \%$, dislocations were emitted from grain boundaries in the samples although the rate of emission increased with hydrogen content of the grain boundary. This resulted in a higher dislocation density being present in the $\mathrm{H}$ containing samples. Both the enhanced dislocation emission and higher dislocation density in the presence of hydrogen are consistent with the hydrogen-enhanced plasticity model [8]. 
The overall distribution of dislocations in the $\mathrm{H}$-free sample is compared to that in samples with hydrogen coverages of $3.2 \mathrm{H} / \mathrm{nm}^{2}$ and $4.8 \mathrm{H} / \mathrm{nm}^{2}$ in Figure 12. The dislocations are identified using the DXA algorithm [56] and colored according to the magnitude of their Burgers vector; Shockley partial dislocations (Burgers vector $1 / 6<112>$ ) are colored yellow, perfect dislocations $(1 / 2<110>)$ in green and Lomer-Cottrell sessile dislocations $(1 / 6<110>)$ in red. In comparing the $\mathrm{H}$-free to the $\mathrm{H}$-containing cases it is seen that the slip system activation sites in the grain boundary are not necessarily the same and those that are common are not activated at the same levels of strain. For example, by comparing the deformation in each grain at strains of 10 and $15 \%$, it can be seen that the number of slip systems activated as well as the number of events is greater in the sample with $3.2 \mathrm{H} / \mathrm{nm}^{2}$ than in $\mathrm{H}$-free material especially in grains 1,3 and 4 . In contrast, the dislocation activity in grain 2 is highest in the $\mathrm{H}$-free case. The near $\sum=$ 3 grain boundary (between grains 4 and 6) shows little activity irrespective of the presence of hydrogen although it is noted that the plane normal of this grain boundary is perpendicular to the loading direction. Assessing the influence on the deformation processes of increasing the hydrogen coverage to $4.8 \mathrm{H} / \mathrm{nm}^{2}$ is complicated as at $10 \%$ strain a crack nucleates on the junction between grains 1, 2, 4 and 5. Nevertheless the majority of dislocation activity still occurs in grains 1, 3 and 4. However, this comparison indicates that the grain boundary cracking occurs at lower strains with increasing coverage of hydrogen.

\subsection{Crack Initiation and propagation}

In assessing the influence of hydrogen on intergranular fracture it is necessary to separate the effects on crack nucleation and crack propagation. As demonstrated in Figure 13, crack initiation on the grain boundary was relatively insensitive to hydrogen coverage, with embryonic 
cracks or excess free volume of length 1 to $2 \mathrm{~nm}$ starting to appear at a strain level of about $5 \%$ irrespective of hydrogen content. It should be noted that all observed cracks were surface cracks that nucleated at triple junctions. Two such cracks can be observed in the samples at $15 \%$ strain shown the Figure 12 , at the 1-2-4-5 junction of the $\mathrm{H}$ free sample and at the 2-3-4 junction of the in the $\mathrm{H}$ containing sample. As demonstrated in Figure 13, crack initiation on the grain boundary was relatively insensitive to hydrogen coverage, with embryonic cracks or excess free volume of length 1 to $2 \mathrm{~nm}$ starting to appear at a strain level of about $5 \%$ irrespective of hydrogen content. This stands in contrast to the results of Chandler and coworkers, who found that the presence of $\mathrm{H}$ reduced the strain at which void nucleation occurred in a grain boundary plane from around $25 \%$ to as little as $15 \%$ [27]. In the current work, the influence of hydrogen was on the crack propagation rate, it increased with increasing hydrogen coverage on the grain boundary. These effects are captured in Figure 13, which shows the length of the largest crack observed as a function of hydrogen coverage and strain level. Furthermore, at a hydrogen coverage of $8 \mathrm{H} / \mathrm{nm}^{2}$ a crack propagated through the sample thickness after $7 \%$ strain as opposed to $20 \%$ strain in the $\mathrm{H}$-free case. Significant plasticity was associated with intergranular crack advance; this result is consistent with experimental observations [66] as well as simulations [26, 67]. The snapshots presented in Figure 14 show crack nucleation and growth in the sample with hydrogen coverage of $4.8 \mathrm{H} / \mathrm{nm}^{2}$. The first crack (Fig. 14a) develops at 10\% deformation at the junction between grains 1, 2, 4, and 5. A larger crack is shown in Figure 14b, which nucleated between grains 2, 3 and 6 and propagated along the grain boundary between grains 3 and 4, and for a short distance along the boundary between grains 4 and 2. Both cracks nucleate in a region of high dislocation activity and close to the location at which a dislocation pile-up forms against the boundary between 
grains 2 and 3. We have observed a limited number of cracks, but these examples point out to the fact that they tend to develop in regions where there are dislocation pile-ups against the $\mathrm{H}$ containing boundary or triple junction.

\section{DISCUSSION}

The results presented in this work represent the first study of the dependence of grain boundary hydrogen coverage on the deformation and failure response on a Ni polycrystalline sample. Although subject to the intrinsic limitations of empirical interatomic potentials and the molecular dynamics simulation technique, the simulations indicate that the presence of hydrogen on the grain boundaries has the following consequences:

1. The introduction of hydrogen on a grain boundary results in changes to the grain boundary structure.

2. Hydrogen clusters form in regions of high free volume in the grain boundary.

3. The yield strength increases with increasing hydrogen coverage on the grain boundary. All samples irrespective of the hydrogen content on the grain boundary show the presence of an upper and lower yield point.

4. After yielding, the emission of dislocations from some grain boundaries is enhanced by the presence of hydrogen.

5. The free volume available in the grain boundary can change with dislocation emission, which in turn influences the clustering of hydrogen in the grain boundary and the emission of dislocations.

6. Crack propagation along the grain boundary but not crack initiation is enhanced by the presence of hydrogen. 
7. The strain to failure, or for an intergranular crack to extend through the simulation sample, decreased in the presence of hydrogen and was dependent on the hydrogen coverage in the grain boundary.

Before considering these findings it is instructive to compare them with experimental observations of hydrogen effects on the deformation and failure of Ni. Experimentally it is found that the presence of hydrogen in $\mathrm{Ni}$ can cause the transition in failure mode from transgranular to intergranular and that the percentage of intergranular fracture is dependent on the hydrogen concentration on the grain boundaries [68,69], although the specific hydrogen concentration needed on each grain boundary to cause intergranular failure remains unknown. The results of these simulations show the same trend. In-situ straining of $\mathrm{Ni}$ in a controlled environment transmission electron microscope shows an increase in the generation of dislocations and an increase in the dislocation mobility [70]. A transition in the failure mode occurred in these in-situ experiments when $S$ was present in the grain boundaries [71]. These effects of hydrogen are combined to explain the observation that the evolved dislocation structure beneath hydrogen-induced intergranular facets in $\mathrm{Ni}$ are more refined and the dislocation density higher than expected for the observed strain to failure [6]. This study proposed that the structure and hydrogen content of the grain boundary were altered by the interactions of hydrogen-bearing dislocations with the grain boundary during the process of slip transfer. These changes resulted in an overall weakening of the grain boundary. This weakening along with the local stress level generated by the dislocation structure in the vicinity of the grain boundary caused intergranular failure by the decohesion mechanism.

Analysis of stress-strain curves generated from tensile tests of polycrystalline $\mathrm{Ni}$ have shown that the presence of hydrogen causes a loss of ductility, an increase in flow stress and an 
increase in the work hardening rate [72]. These effects were not apparent in the simulation results. These differences can be attributed to the differences in the methodology, the size and form of the samples, locating the hydrogen only on the grain boundaries, retaining the hydrogen coverage in the grain boundary constant, and the test conditions. The initial increase in the stress required to emit a dislocation from a grain boundary can be attributed to hydrogen occupying sites of free volume, which have been shown to be the sites for dislocation emission in the absence of hydrogen [65]. However, once activated these sites emit more dislocations when hydrogen is present although this is not due to a decrease in the stress to activate the grain boundary dislocation source as the lower yield point does not change significantly with hydrogen coverage. This finding is consistent with experimental findings of hydrogen-enhanced dislocation generation [39, 73] as well as slip transfer across grain boundaries [6, 7, 74]. However, both the simulations and experiments find that the strain to failure is reduced in the presence of hydrogen on the grain boundaries and decreases with increasing hydrogen concentration. For example, Ni-201 containing 2000 ppm of internal hydrogen, exhibited a strain to failure of just $13 \%$ [72].

The change in the structure of the grain boundary simply due to the introduction of hydrogen and its further modification through the emission of dislocations provides new insight as to how hydrogen and the plasticity could combine to cause the cohesive strength of a specific grain boundary to become the weak link in the system and therefore the preferred site for crack nucleation. Experimentally the increase in disorder or free volume in the grain boundary is inferred from observed structural changes in the grain boundary following dislocation interactions with it. However, the connection of dislocation emission to regions of high free volume has not been achieved experimentally. Once nucleated a crack propagates along the 
weakest grain boundary provided it experienced an appropriate level of stress. This observation raises the interesting question about the level of coverage of hydrogen that is needed on the grain boundary for the presence of hydrogen alone to reduce the cohesive strength sufficiently to make it the weakest link in the system. It also suggests that the reduction in the cohesive strength necessary to make a grain boundary the weakest link is, for the same hydrogen coverage, dependent on the grain boundary type. Unfortunately, studies to assess the magnitude of the grain boundary cohesive energy as a function of hydrogen content and grain boundary type are not common. Most studies have shown that the ideal work of separation decreases almost linearly with increasing hydrogen coverage, dropping by $\sim 45 \%$ at one-half monolayer of hydrogen coverage $[75,76]$. However, these studies neglect plasticity effects prior to crack initiation and have not been conducted as a function of grain boundary type. Shuai et al. have reported that the magnitude of the reduction of the cohesive energy of grain boundaries as a function of hydrogen coverage in $\mathrm{Fe}$ is sensitive to the grain boundary type [77]. They have questioned if the levels attainable under experimental hydrogen charging conditions will yield the coverages necessary to reduce the cohesive strength sufficiently. Our results show that significant effects on dislocation emission are already observed for a coverage of $3.2 \mathrm{H} / \mathrm{nm}^{2}$ corresponding to approximately $15 \%$ of a monolayer.

Our results indicate that beyond the compositional effect of hydrogen on the grain boundary cohesion, structural effects on the grain boundary due to hydrogen and the deformation process can play a critical role. Martin et al. [6] and Wang et al. [7] introduced the concept of a increased structural disorder due to hydrogen-enhanced slip transfer across grain boundaries as contributing to the reduction of the cohesive strength of the grain boundary. Similarly, in the case of liquid metal embrittlement it has been suggested that structural as well as compositional 
changes to the grain boundary are responsible for the failure path being along grain boundaries $[78,79]$.

Our results also suggest preferential crack growth at sites at which a dislocation pile-up impinges on the grain boundary and the dislocations are not accommodated in the grain boundary. For random boundaries, these pile-ups contain increased number of dislocations for increased hydrogen coverage. As the magnitude of the stress ahead of a dislocation pile-up is related to the number of dislocations in it, this result implies an increase in the local stress state at the grain boundary. As the simulations only allow for faster dislocation emission from grain boundary sources, the actual effect is expected to be greater and to develop more rapidly when the effect of hydrogen on the dislocation mobility is included. This increase in the local stress at the grain boundary supports the interpretation of experimental findings summarized recently by Robertson [8].

\section{CONCLUSIONS}

Based on these simulations the following conclusions can be drawn: $\mathrm{H}$ impurities that segregate to the grain boundaries change the grain boundary structure, creating regions of high free volume at the sites of $\mathrm{H}$ clusters. $\mathrm{H}$ in the grain boundaries, especially at regions of high free volume, constitute favored sites for dislocation nucleation. A positive trend in yield strength was observed, wherein more $\mathrm{H}$ caused initial yield to occur at higher stress levels. This effect can be caused by $\mathrm{H}$ occupying the free volume in the boundaries. This trend seems to be reversed for higher deformation levels with dislocation density values enhanced by the addition of hydrogen in the sample grain boundaries. This occurs for stresses when the $\mathrm{H}$ filled sites are activated for dislocation emission. Once cracks are nucleated in the grain boundaries, their growth is greatly enhanced by the presence of intergranular hydrogen. The presence of 
dislocation pile-ups in random grain boundaries is enhanced by hydrogen. Significant plasticity due to enhanced emission of dislocations from grain boundary sources is observed in the presence of hydrogen, even as cracks nucleate and grow. Crack growth seems to be enhanced in locations where the dislocations pile up against the boundaries.

Acknowledgements: The authors would like to thank Laura Smith for her previous work and technical contributions that aided in the completion of this work. This work was supported by the Department of Energy, Office of Basic Energy Sciences, under grant DE-FG02-08ER46525. The authors acknowledge Advanced Research Computing at Virginia Tech for providing computational resources and technical support that have contributed to the results reported within this paper. URL: http://www.arc.vt.edu. 


\section{REFERENCES}

[1] R.P. Gangloff, in: B. Somerday, P. Sofronis, R. Jones (Eds.) Proceedings of the 2008 International Hydrogen Conference - Effects of Hydrogen on Materials, ASM International, Jackson Hole, Wyoming, 2009, pp. 1-21.

[2] I.M. Robertson, D. Lillig, P.J. Ferreira, in: B. Somerday, P. Sofronis, R. Jones (Eds.) Proceedings of the 2008 International Hydrogen Conference - Effects of Hydrogen on Materials, ASM International, Jackson Hole, Wyoming, 2009, pp. 22 -37.

[3] S. Bechtle, M. Kumar, B.P. Somerday, M.E. Launey, R.O. Ritchie, Acta Materialia, 57 (2009) 4148-4157.

[4] C.J. McMahon Jr, Engineering Fracture Mechanics, 68 (2001) 773-788.

[5] C.J. McMahon Jr, Interface Science, 12 (2004) 141-146.

[6] M.L. Martin, B.P. Somerday, R.O. Ritchie, P. Sofronis, I.M. Robertson, Acta Materialia, 60 (2012) 2739-2745.

[7] S. Wang, M.L. Martin, P. Sofronis, S. Ohnuki, N. Hashimoto, I.M. Robertson, Acta Materialia, 69 (2014) 275-282.

[8] I.M. Robertson, P. Sofronis, A. Nagao, M.L. Martin, S. Wang, D.W. Gross, K.E. Nygren, Metallurgical and Materials Transactions a-Physical Metallurgy and Materials Science, 46A (2015) 2323-2341.

[9] H. Van Swygenhoven, A. Caro, D. Farkas, in: 5th International Conference on Nanostructured Materials (NANO 2000), Sendai, Japan, 2000, pp. 1513-1516. [10] H. Van Swygenhoven, A. Caro, D. Farkas, in: International Conference on the Fundamentals of Plastic Deformation, Gaithersburg, Maryland, 2000, pp. 440-444. [11] H. Van Swygenhoven, D. Farkas, A. Caro, Physical Review B, 62 (2000) 831-838. [12] D. Wolf, V. Yamakov, S.R. Phillpot, A. Mukherjee, H. Gleiter, Acta Materialia, 53 (2005) 1. [13] D. Wolf, V. Yamakov, S.R. Phillpot, A.K. Mukherjee, Z Metallkd, 94 (2003) 1091-1097.

[14] F. Sansoz, J.F. Molinari, Acta Mater, 53 (2005) 1931-1944.

[15] Y. Mishin, M. Asta, J. Li, Acta Materialia, 58 (2010) 1117-1151.

[16] D.L. McDowell, International Journal of Plasticity, 26 (2010) 1280-1309.

[17] A.J. Cao, Y.G. Wei, J Appl Phys, 102 (2007).

[18] N.Q. Vo, R.S. Averback, P. Bellon, S. Odunuga, A. Caro, Phys Rev B, 77 (2008).

[19] D. Farkas, Current Opinion in Solid State \& Materials Science, 17 (2013) 284-297.

[20] P.M. Piaggi, E.M. Bringa, R.C. Pasianot, N. Gordillo, M. Panizo-Laiz, J. del Rio, C.G. de Castro, R. Gonzalez-Arrabal, Journal of Nuclear Materials, 458 (2015) 233-239.

[21] Y. Yu, X.L. Shu, Y.N. Liu, G.H. Lu, Journal of Nuclear Materials, 455 (2014) 91-95.

[22] H. Wang, D.S. Xu, R. Yang, Philosophical Magazine Letters, 94 (2014) 779-785.

[23] J. Song, W.A. Curtin, Acta Materialia, 68 (2014) 61-69.

[24] J. Song, W.A. Curtin, Nature Materials, 12 (2013) 145-151.

[25] J.H. Shim, W.S. Ko, J.Y. Suh, Y.S. Lee, B.J. Lee, Metals and Materials International, 19 (2013) 1221-1225.

[26] K.N. Solanki, D.K. Ward, D.J. Bammann, Metall Mater Trans A, 42a (2011) 340-347.

[27] M.Q. Chandler, M.F. Horstemeyer, M.I. Baskes, G.J. Wagner, P.M. Gullett, B. Jelinek, Acta Mater, 56 (2008) 619-631.

[28] M. Ruda, D. Farkas, J. Abriata, Hydrogen Energy Progress Xii, Vols 1-3, (1998) 21992206. 
[29] M. Ruda, D. Farkas, J. Abriata, Physical Review B, 54 (1996) 9765-9774. [30] D. Farkas, R. Nogueira, M. Ruda, B. Hyde, Metallurgical and Materials Transactions aPhysical Metallurgy and Materials Science, 36A (2005) 2067-2072.

[31] W.T. Geng, A.J. Freeman, R. Wu, C.B. Geller, J.E. Raynolds, Physical Review B, 60 (1999) 7149-7155.

[32] T. Hickel, R. Nazarov, E.J. McEniry, G. Leyson, B. Grabowski, J. Neugebauer, Jom, 66 (2014) 1399-1405.

[33] H.K. Birnbaum, P. Sofronis, Mater. Sci. Eng. A, Struct. Mater., Prop. Microstruct. Process., A176 (1994) 191-202.

[34] J. Song, M. Soare, W.A. Curtin, Modelling and Simulation in Materials Science and Engineering, 18 (2010) 045003.

[35] C.J. McMahon Jr, Acta Metallurgica, 14 (1966) 839-845.

[36] M. Dadfarnia, P. Novak, D.C. Ahn, J.B. Liu, P. Sofronis, D.D. Johnson, I.M. Robertson, Adv Mater, 22 (2010) 1128-1135.

[37] D. Delafosse, T. Magnin, Engineering Fracture Mechanics, 68 (2001) 693-729.

[38] C. Mei Qiang, J.B. Douglas, M.F. Horstemeyer, Modelling and Simulation in Materials Science and Engineering, 21 (2013) 055028.

[39] I.M. Robertson, H.K. Birnbaum, P. Sofronis, Hydrogen Effects On Plasticity, in: J.P. Hirth, L. Kubin (Eds.) Dislocations in Solids, Elsevier, New York, 2009, pp. 249-293.

[40] D.P. Abraham, C.J. Altstetter, Metallurgical and Materials Transactions A (Physical Metallurgy and Materials Science), 26A (1995) 2859.

[41] S. Wang, N. Hashimoto, Y. Wang, S. Ohnuki, Acta Materialia, 61 (2013) 4734-4742. [42] J. Song, W.A. Curtin, Acta Materialia, 59 (2011) 1557-1569.

[43] S. Li, Y. Li, Y.-C. Lo, T. Neeraj, R. Srinivasan, X. Ding, J. Sun, L. Qi, P. Gumbsch, J. Li, International Journal of Plasticity, - 74 (2015) - 191.

[44] T. Neeraj, R. Srinivasan, J. Li, Acta Materialia, 60 (2012) 5160-5171.

[45] R. Srinivasan, T. Neeraj, Jom, 66 (2014) 1377-1382.

[46] M.L. Martin, I.M. Robertson, P. Sofronis, Acta Materialia, 59 (2011) 3680-3687.

[47] M.S. Daw, M.I. Baskes, Physical Review Letters, 50 (1983) 1285-1288.

[48] M.S. Daw, M.I. Baskes, Physical Review B, 29 (1984) 6443--6453.

[49] A.F. Voter, Chen, S.P, MRS Symposia Proceedings, 82 (1987) 175.

[50] A. Ramasubramaniam, M. Itakura, E.A. Carter, Physical Review B, 79 (2009).

[51] H. Van Swygenhoven, M. Spaczer, A. Caro, D. Farkas, Physical Review B, 60 (1999) 22-25.

[52] H. Van Swygenhoven, A. Caro, D. Farkas, Materials Science and Engineering aStructural Materials Properties Microstructure and Processing, 309 (2001b) 440-444. [53] S. Plimpton, J Comput Phys, 117 (1995) 1-19.

[54] C.L. Kelchner, S.J. Plimpton, J.C. Hamilton, Physical Review B, 58 (1998) 11085-11088.

[55] A. Stukowski, Modelling and Simulation in Materials Science and Engineering, 18 (2010).

[56] A. Stukowski, K. Albe, Model Simul Mater Sc, 18 (2010).

[57] A. Henderson, (2007).

[58] T.M. Harris, R.M. Latanision, Metallurgical Transactions a-Physical Metallurgy and Materials Science, 22 (1991) 351-355.

[59] A.M. Brass, A. Chanfreau, Acta Materialia, 44 (1996) 3823-3831.

[60] A. Pedersen, H. Jonsson, Acta Materialia, 57 (2009) 4036-4045. 
[61] A. Oudriss, J. Creus, J. Bouhattate, E. Conforto, C. Berziou, C. Savall, X. Feaugas, Acta Materialia, 60 (2012) 6814-6828.

[62] A. Oudriss, J. Creus, J. Bouhattate, C. Savall, B. Peraudeau, X. Feaugas, Scripta Materialia, $66(2012) 37-40$.

[63] B.O. Hoch, A. Metsue, J. Bouhattate, X. Feaugas, Computational Materials Science, 97 (2015) 276-284.

[64] W.T. Geng, A.J. Freeman, G.B. Olson, Y. Tateyama, T. Ohno, Materials Transactions, 46 (2005) 756-760.

[65] D. Farkas, L. Patrick, Philos Mag, 89 (2009) 3435-3450.

[66] A. Alvaro, I.T. Jensen, N. Kheradmand, O.M. Lovvik, V. Olden, Int J Hydrogen Energ, 40 (2015) 16892-16900.

[67] W. Barrows, R. Dingreville, D. Spearot, Mat Sci Eng a-Struct, 650 (2016) 354-364.

[68] D.H. Lassila, H.K. Birnbaum, Acta Metall., 36 (1988) 2821-2825.

[69] D.H. Lassila, H.K. Birnbaum, Acta Metall., 35 (1987) 1815-1822.

[70] I.M. Robertson, H.K. Birnbaum, Acta Metallurgica, 34 (1986) 353-366.

[71] T.C. Lee, I.M. Robertson, H.K. Birnbaum, Acta Metallurgica, 37 (1989) 407-415.

[72] B.A. Wilcox, G.C. Smith, Acta Metall Mater, 13 (1965) 331-\&.

[73] I.M. Robertson, Engineering Fracture Mechanics, 68 (2001) 671-692.

[74] I. Robertson, P. Sofronis, A. Nagao, M.L. Martin, S. Wang, D.W. Gross, K.E. Nygren, Metall and Mat Trans A, (2015) 1-19.

[75] D.E. Jiang, E.A. Carter, Acta Mater, 52 (2004) 4801-4807.

[76] D.H. Lassila, H.K. Birnbaum, Acta Metall Mater, 34 (1986) 1237-1243.

[77] S. Wang, M. Martin, I. Robertson, P. Sofronis, Acta Materialia, under review (2015).

[78] J. Luo, H. Cheng, K.M. Asl, C.J. Kiely, M.P. Harmer, Science, 333 (2011) 1730.

[79] M.L. Martin, T. Auger, D.D. Johnson, I.M. Robertson, J Nucl Mater, 426 (2012) 71-77. 


\section{Figure Captions:}

1. Microstructure of the relaxed sample colored by centro-symmetry parameter.

2. Detail of the grain boundary between grains 1 and 5 (a) without and (b) with $\mathrm{H}$ impurities showing significant changes in the grain boundary structure and $\mathrm{H}$ clustering.

3. Clustering of $\mathrm{H}$ atoms in a selected boundary containing $6.4 \mathrm{H} / \mathrm{nm} 2$. The $\mathrm{Ni}$ atoms are deleted for clarity and the clusters are highlighted by circles of varying colors according to the number of $\mathrm{H}$ atoms in the cluster.

4. Average cluster size in the relaxed grain boundaries as a function of $\mathrm{H}$ coverage.

5. Frequency of grain boundary $\mathrm{H}$ clusters in the sample with grain boundary coverage of $8.0 \mathrm{H}$ atoms $/ \mathrm{nm} 2$.

6. Stress-strain behavior of samples with different $\mathrm{H}$ coverage levels in the grain boundaries.

7. Yield stress observed as a function of $\mathrm{H}$ coverage in the grain boundary.

8. Average cluster size in the sample with $4.8 \mathrm{H} / \mathrm{nm} 2$ grain boundary coverage as a function of simulation time with and without applied strain.

9. Changes in the average grain boundary hydrogen cluster size for varying $\mathrm{H}$ coverage and strain.

10. (a) A dislocation emitted into grain 3 from $\mathrm{H}$ clusters in the grain boundary between grains 2 and 3 for $8 \mathrm{H} / \mathrm{nm} 2$ grain boundary coverage and $3 \%$ strain. The arrow indicates the direction of motion. (b) The same area for the sample without $\mathrm{H}$.

11. Evolution of the dislocation density as a function of strain for samples without $\mathrm{H}$ and two different levels of $\mathrm{H}$ grain boundary coverage.

12. Dislocation structures observed for samples without grain boundary $H$ (left) and 3.2 $\mathrm{H} / \mathrm{nm} 2$ (right). Shockley partials are shown in yellow and full dislocations in green. Darker gray shaded areas are stacking faults. Deformation levels are 5\% 10\% and 15\% from top.

13. Crack initiation and growth as a function of applied strain for various levels of $\mathrm{H}$ coverage at the grain boundary.

14. (a) Dislocation pile ups and crack initiation observed in $4.8 \mathrm{H} / \mathrm{nm} 2$ sample deformed $10 \%$. A crack starts to nucleate near the triple junction of grains 1, 2 and 4. (b) $4.8 \mathrm{H} / \mathrm{nm} 2$ sample deformed $15 \%$. A crack nucleates and grows near the triple junction of grains 2 , 3 and 4. Dislocations with Burgers vector $1 / 6<112>$ are yellow, $1 / 2<110>$ are green, and $1 / 6<110>$ are red. Darker gray shaded areas are stacking faults. Both cracks appear at sites where dislocations pile up against a boundary. 


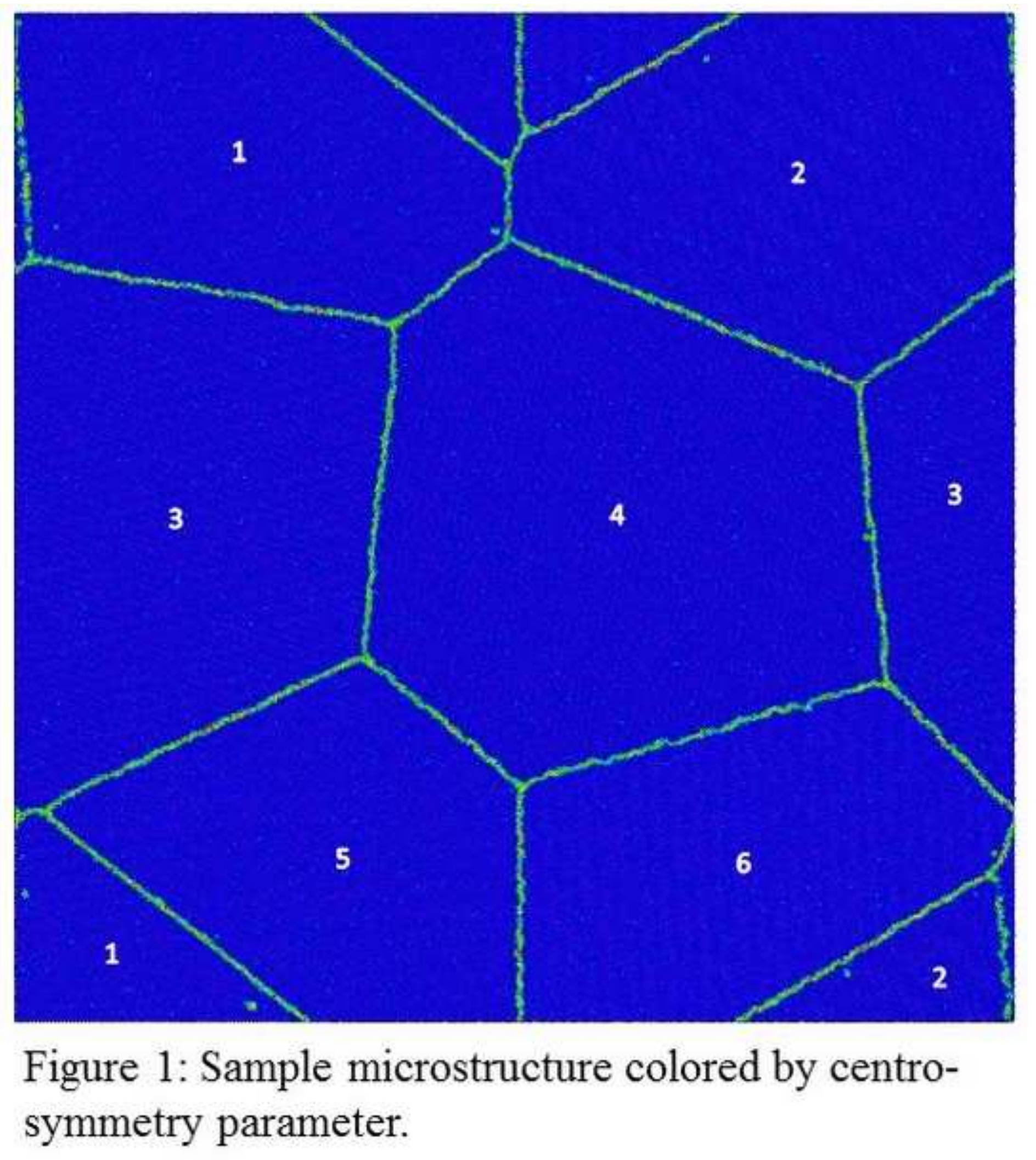

Figure 1: Sample microstructure colored by centrosymmetry parameter. 


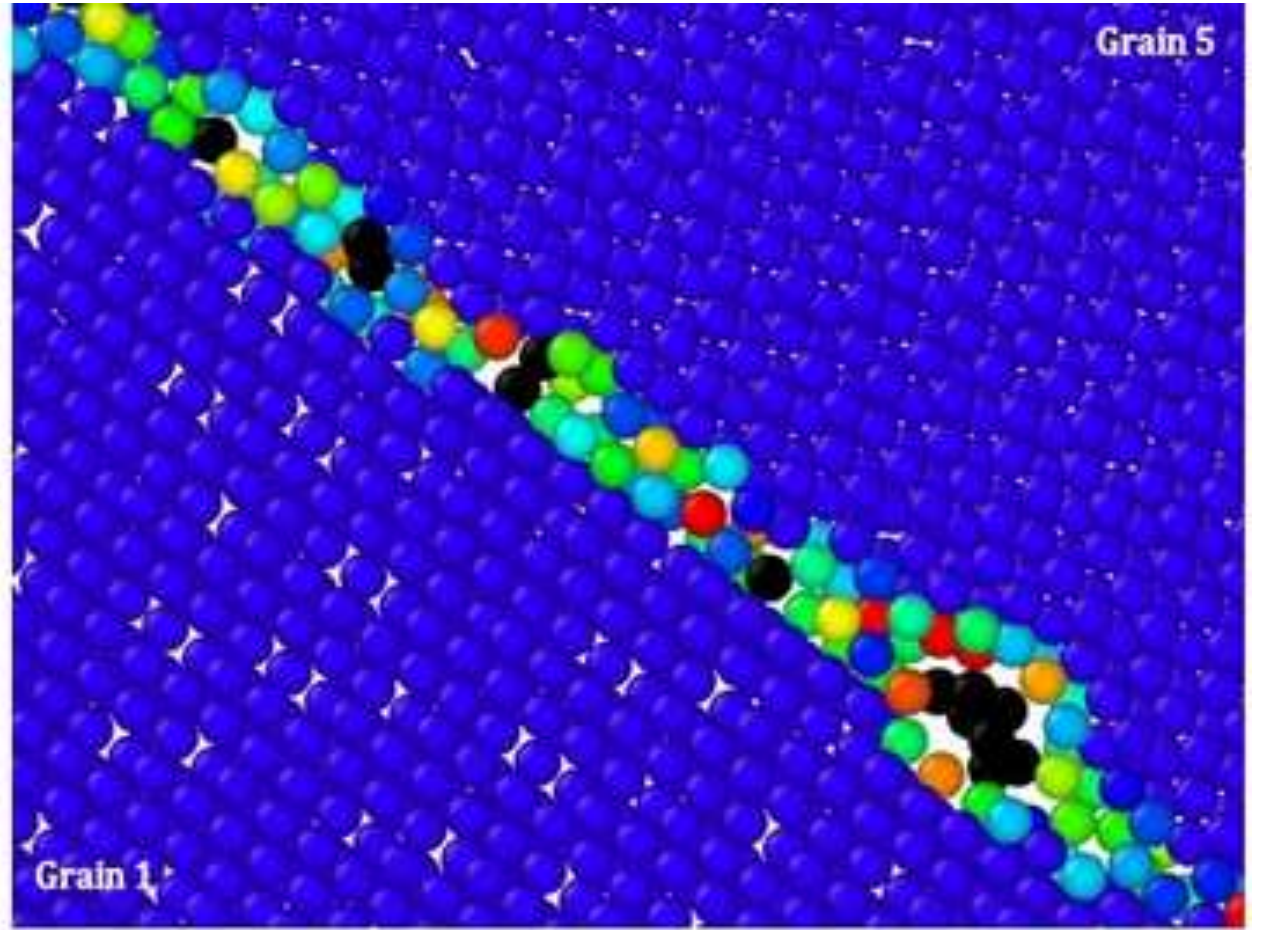

(b)

Figure 2: Detail of the grain boundary between grains 1 and 5 (a) without and (b) with $\mathrm{H}$ impurities

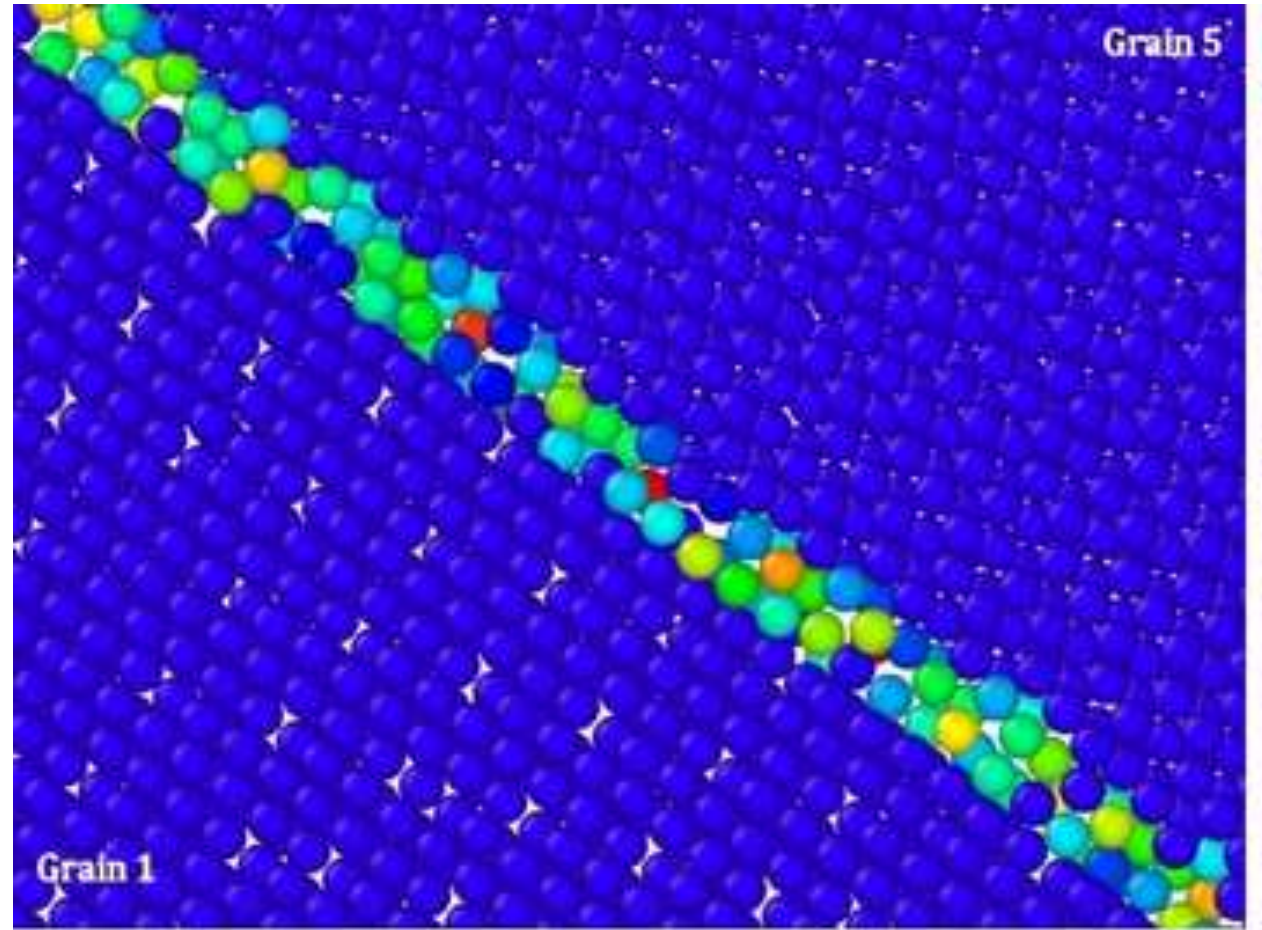

(a) showing significant changes in the grain boundary structure and $\mathrm{H}$ clustering. 

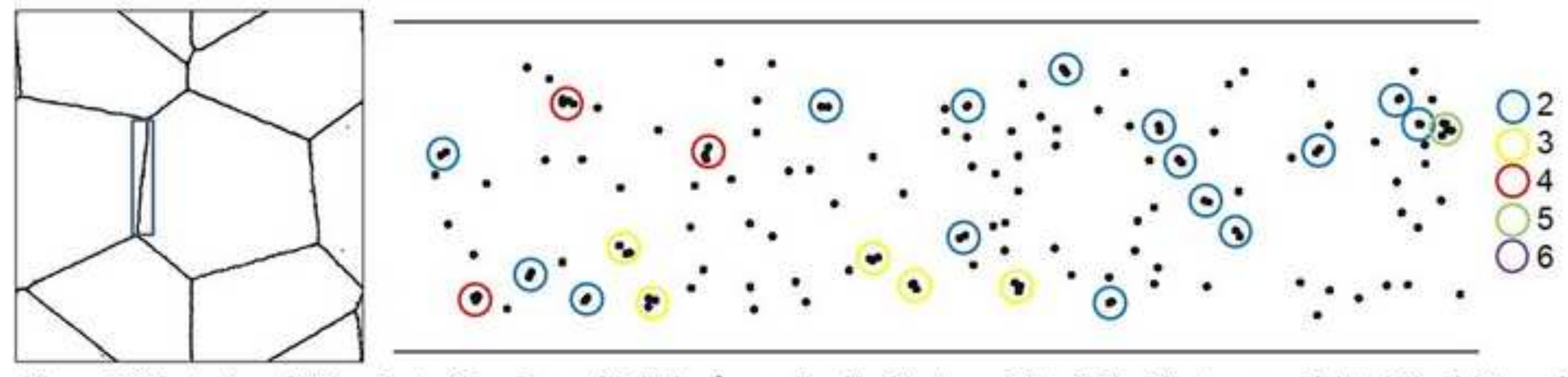

Figure 3: Clustering of $\mathrm{H}$ in selected boundary of $6.4 \mathrm{H} / \mathrm{nm}^{2}$ sample with $\mathrm{Ni}$ atoms deleted. The $\mathrm{Ni}$ atoms are deleted for clarity and the clusters are highlighted by circles of varying colors according to the number of $\mathrm{H}$ atoms in the cluster. 


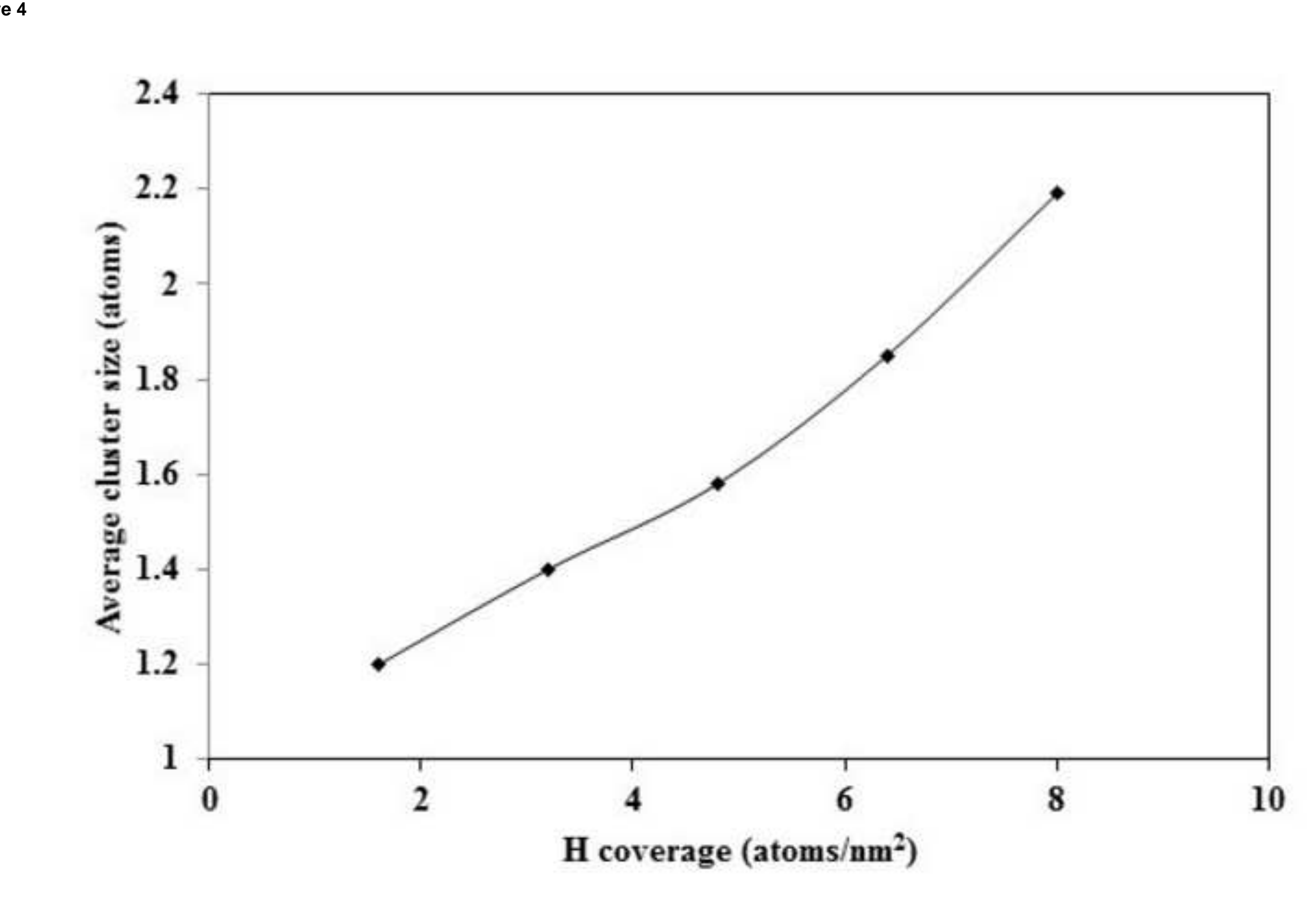

Fig. 4: Average cluster size in the relaxed grain
boundaries as a function of $\mathrm{H}$ coverage. Fig. 4: Average cluster size in the relaxed grain
boundaries as a function of $\mathrm{H}$ coverage.

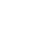

.

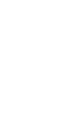

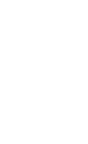

(1)

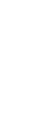

\author{
(
}




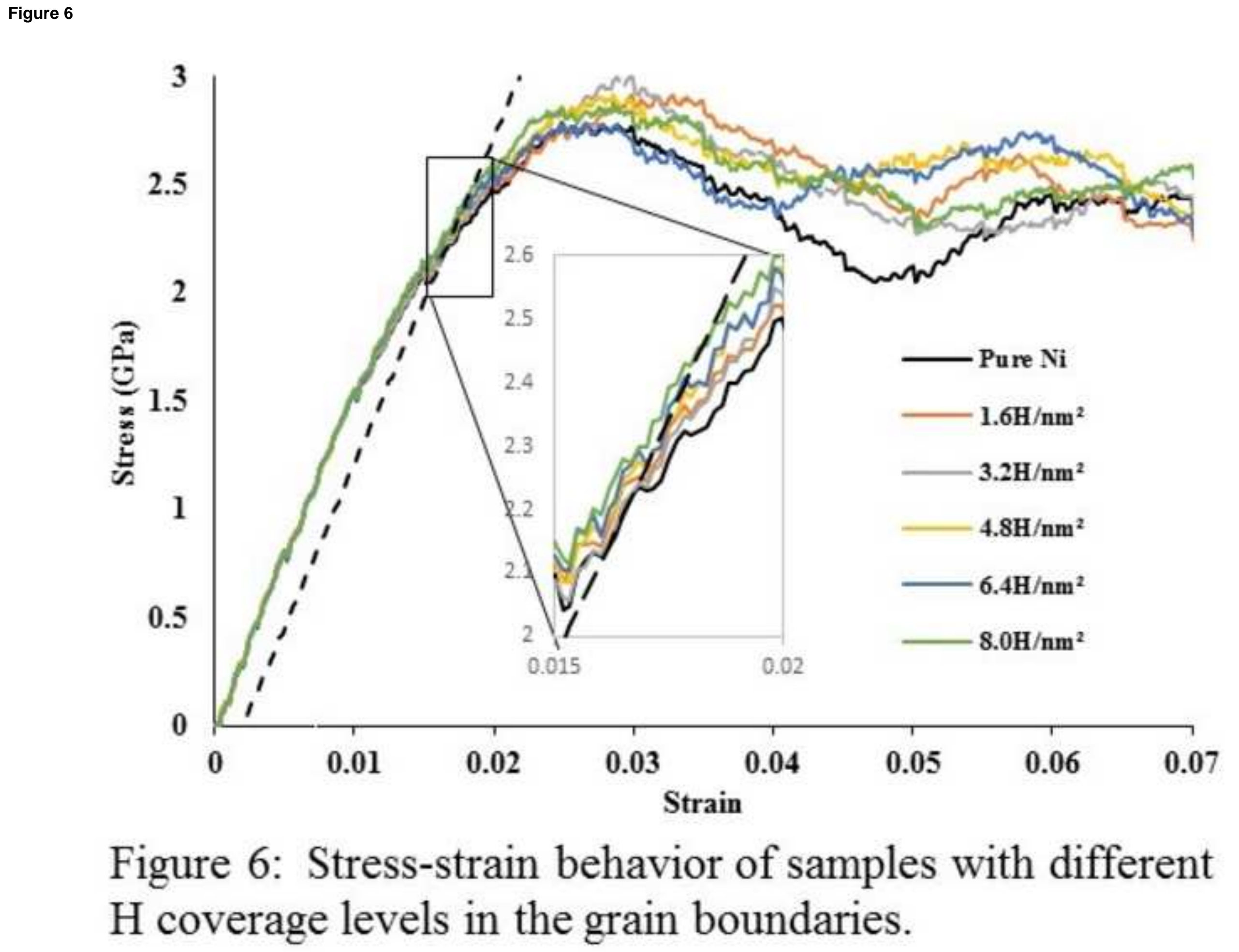

Figure 6: Stress-strain behavior of samples with different $\mathrm{H}$ coverage levels in the grain boundaries.

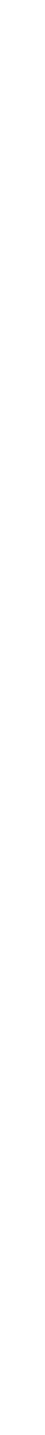

.

(⿸丆口

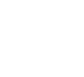




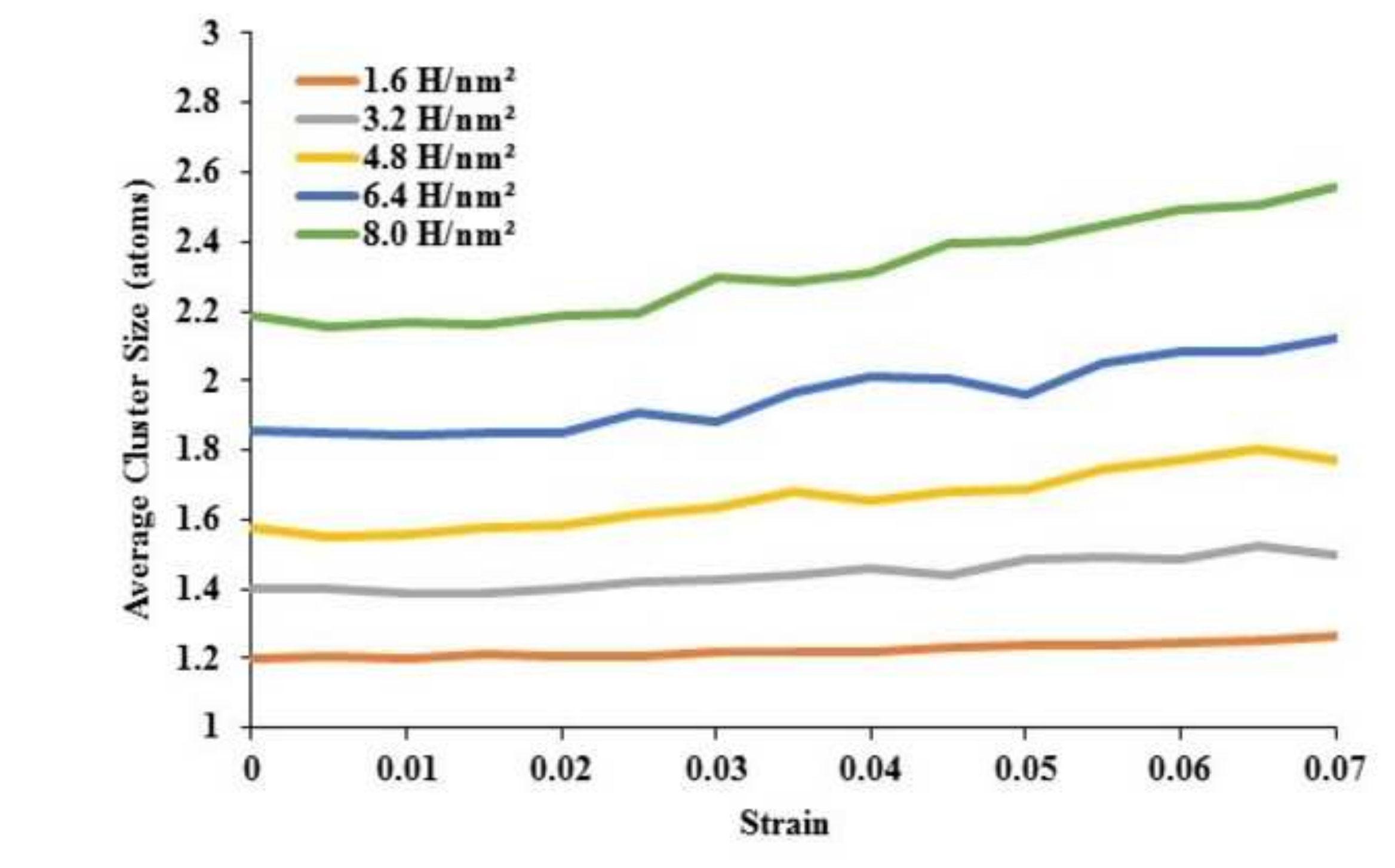

Figure 9: Change in average grain boundary hydrogen

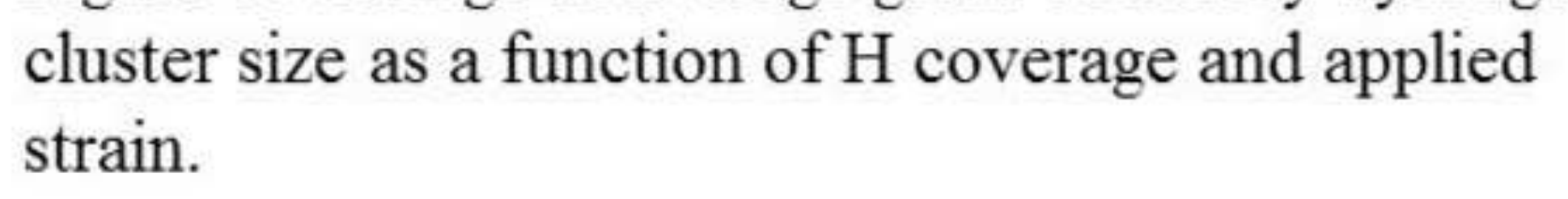
strain.

re strain.

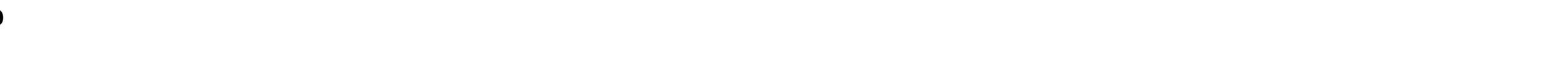

.

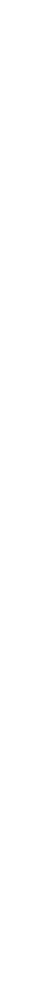

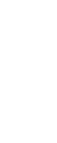




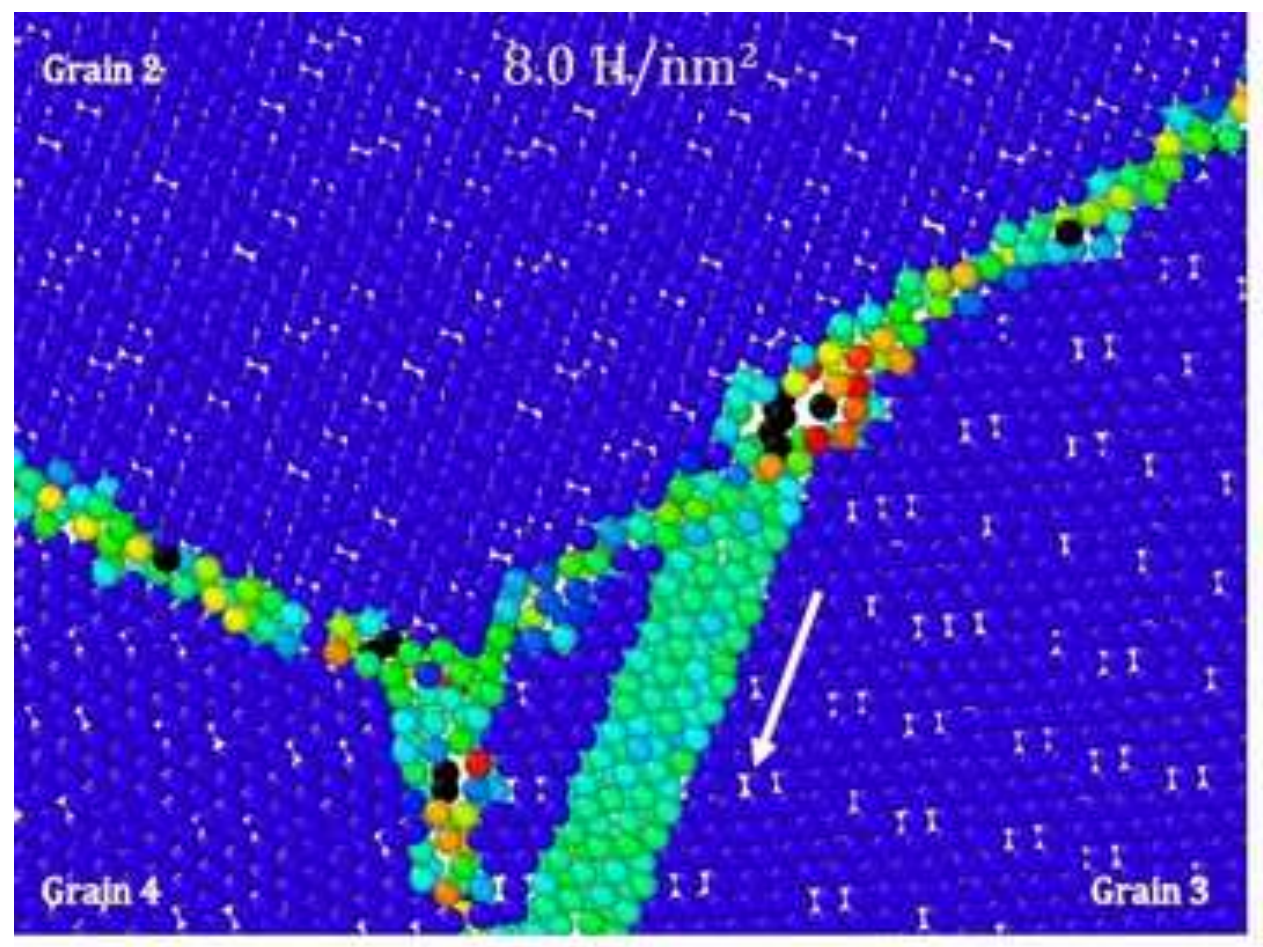

(a)

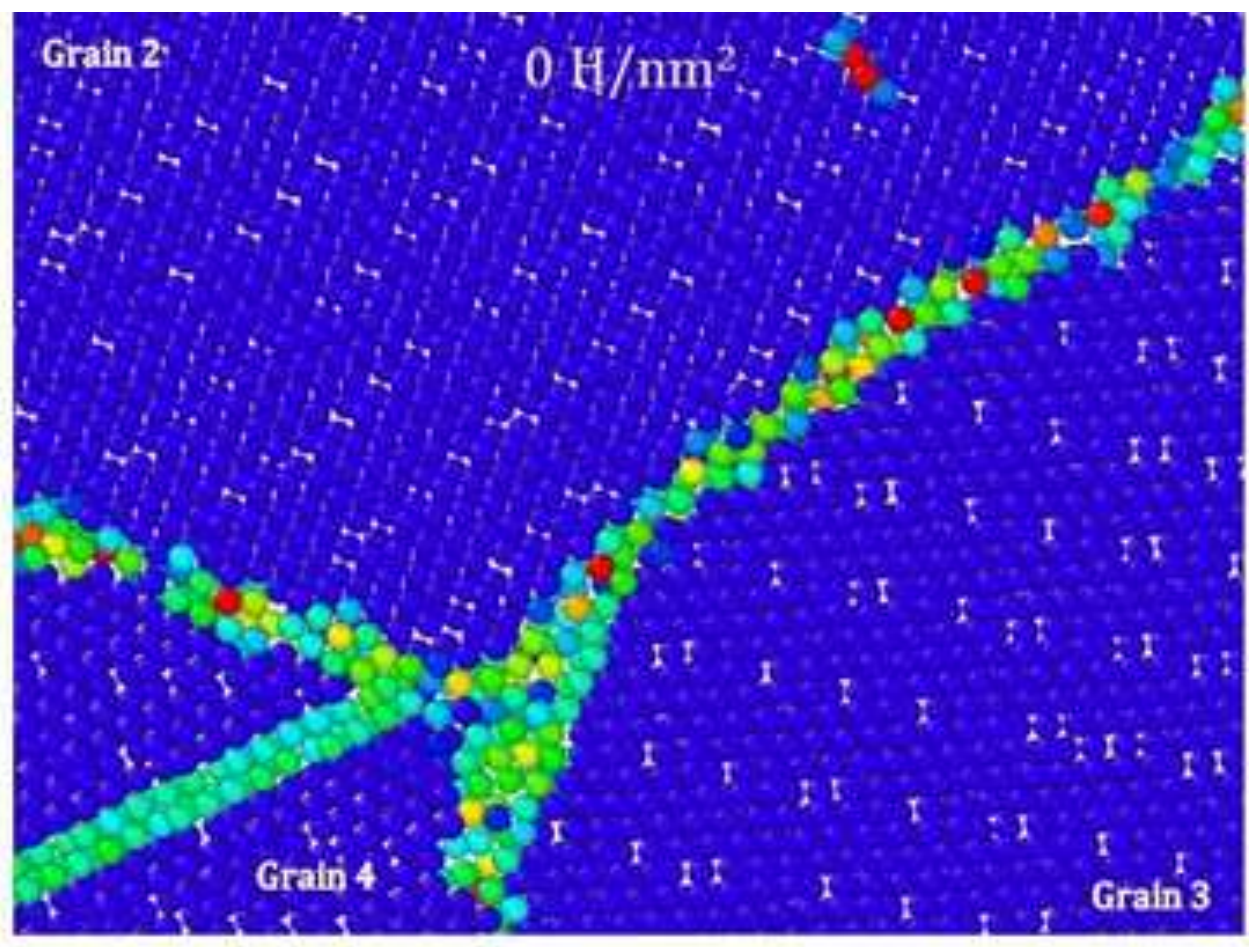

(b)

Figure 10: (a) A dislocation emitted into grain 3 from $\mathrm{H}$ clusters in the grain boundary between grains 2 and 3 for $8 \mathrm{H} / \mathrm{nm}^{2}$ grain boundary coverage and $3 \%$ strain. The arrow indicates the direction of motion. (b) The same area for the sample without $\mathrm{H}$. 


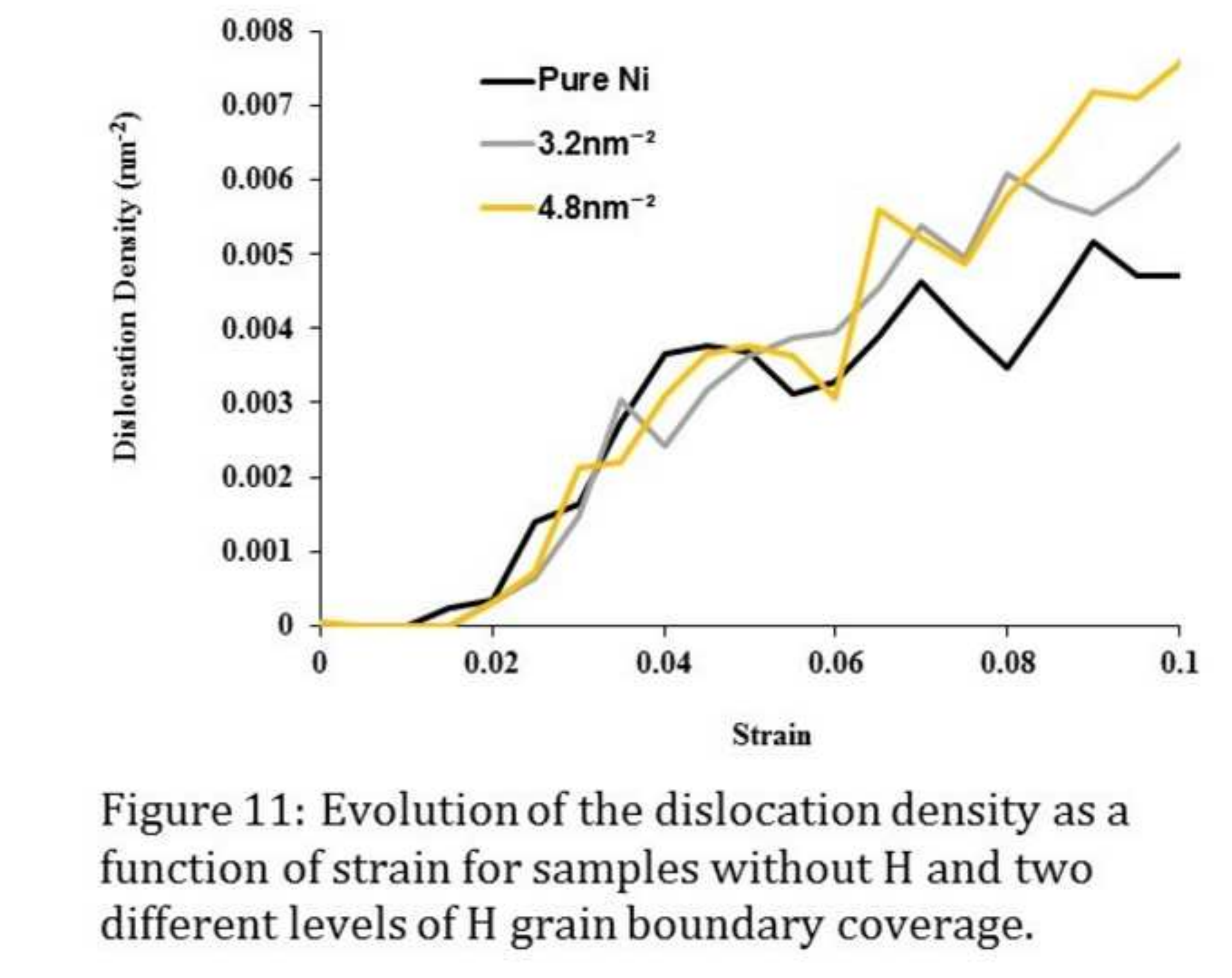

Figure 11: Evolution of the dislocation density as a

function of strain for samples without $\mathrm{H}$ and two different levels of $\mathrm{H}$ grain boundary coverage.

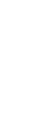

济

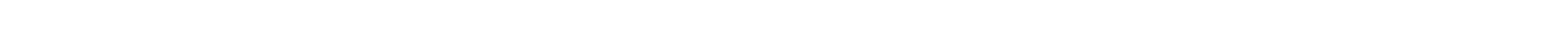

(2)

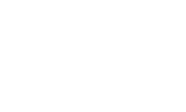

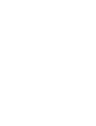

$\sqrt{2}$ (1) different levels of $\mathrm{H}$ grain boundary coverage.

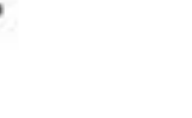

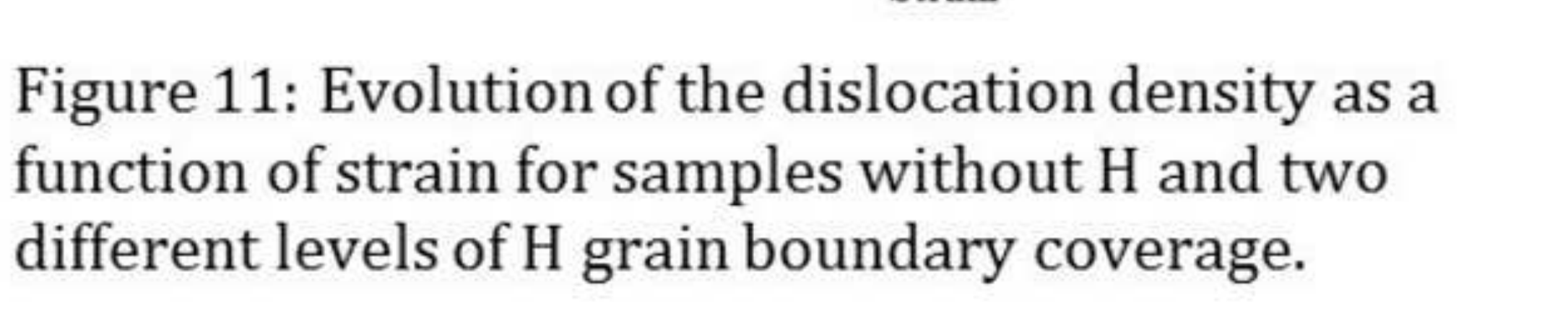

.

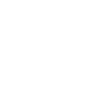

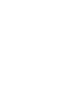



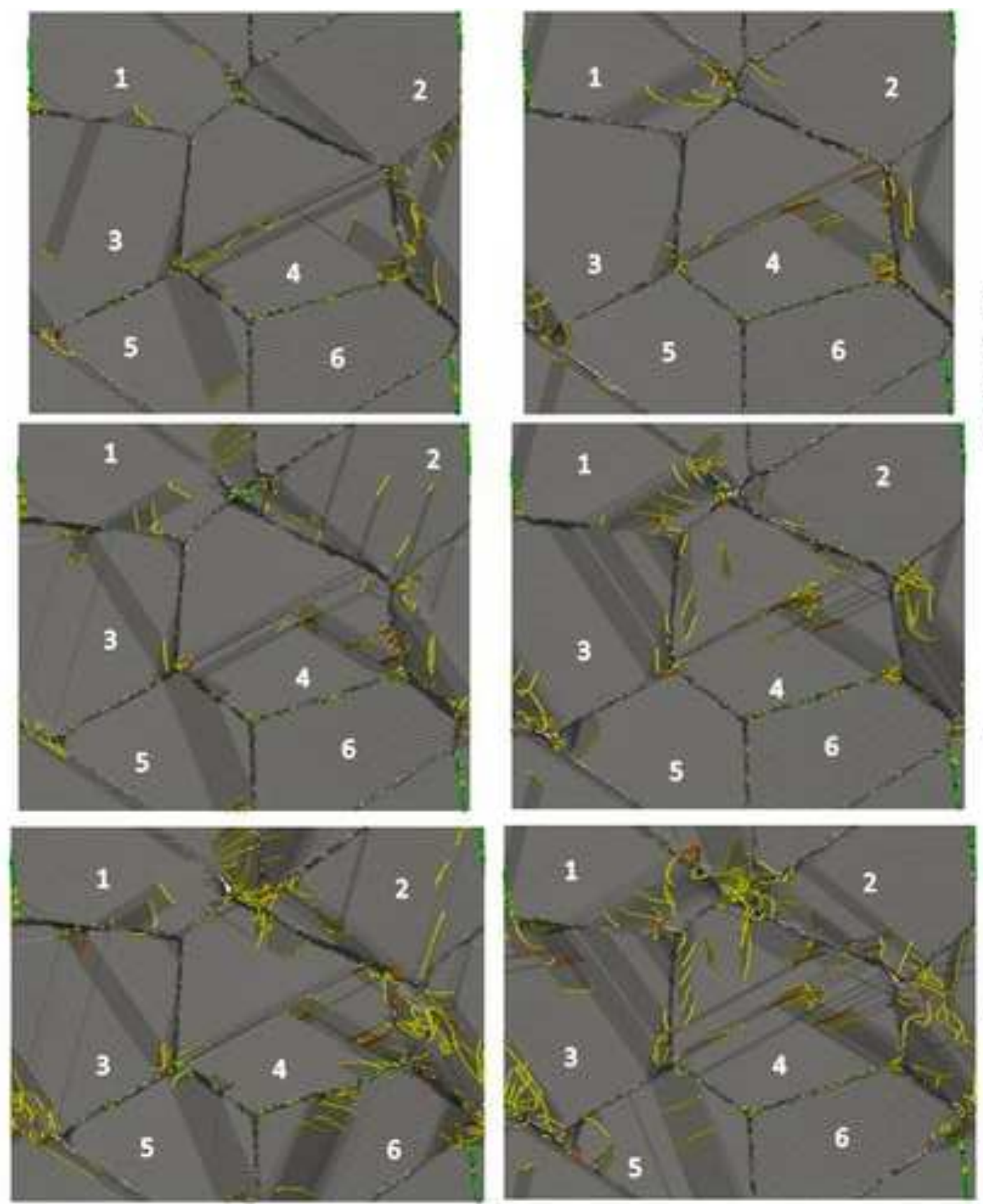

$\leftarrow$ Tensile Direction $\rightarrow$
Figure 12: Dislocation structures observed for samples without grain boundary $\mathrm{H}$ (left) and 3.2 $\mathrm{H} / \mathrm{nm}^{2}$ (right). Dislocations
Burgers vector magnitude (lattice units):

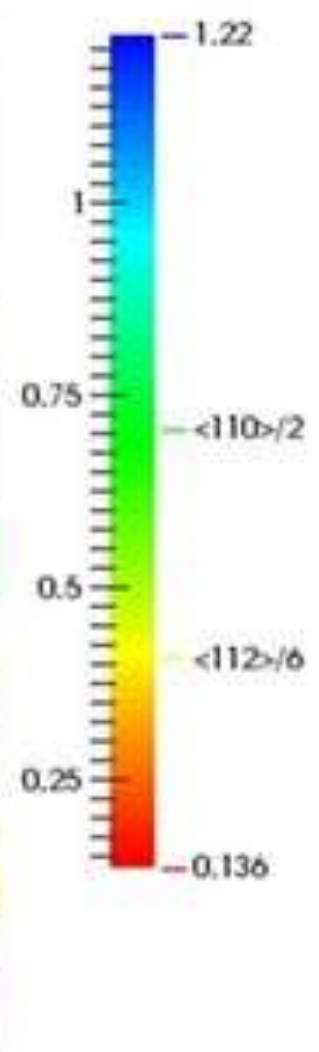
with Burgers vector $1 / 6<112>$ are yellow, $1 / 2<110>$ are green, and $1 / 6<110>$ are red. Darker gray shaded areas are stacking faults. Deformation levels are $5 \%$ $10 \%$ and $15 \%$ from top. 


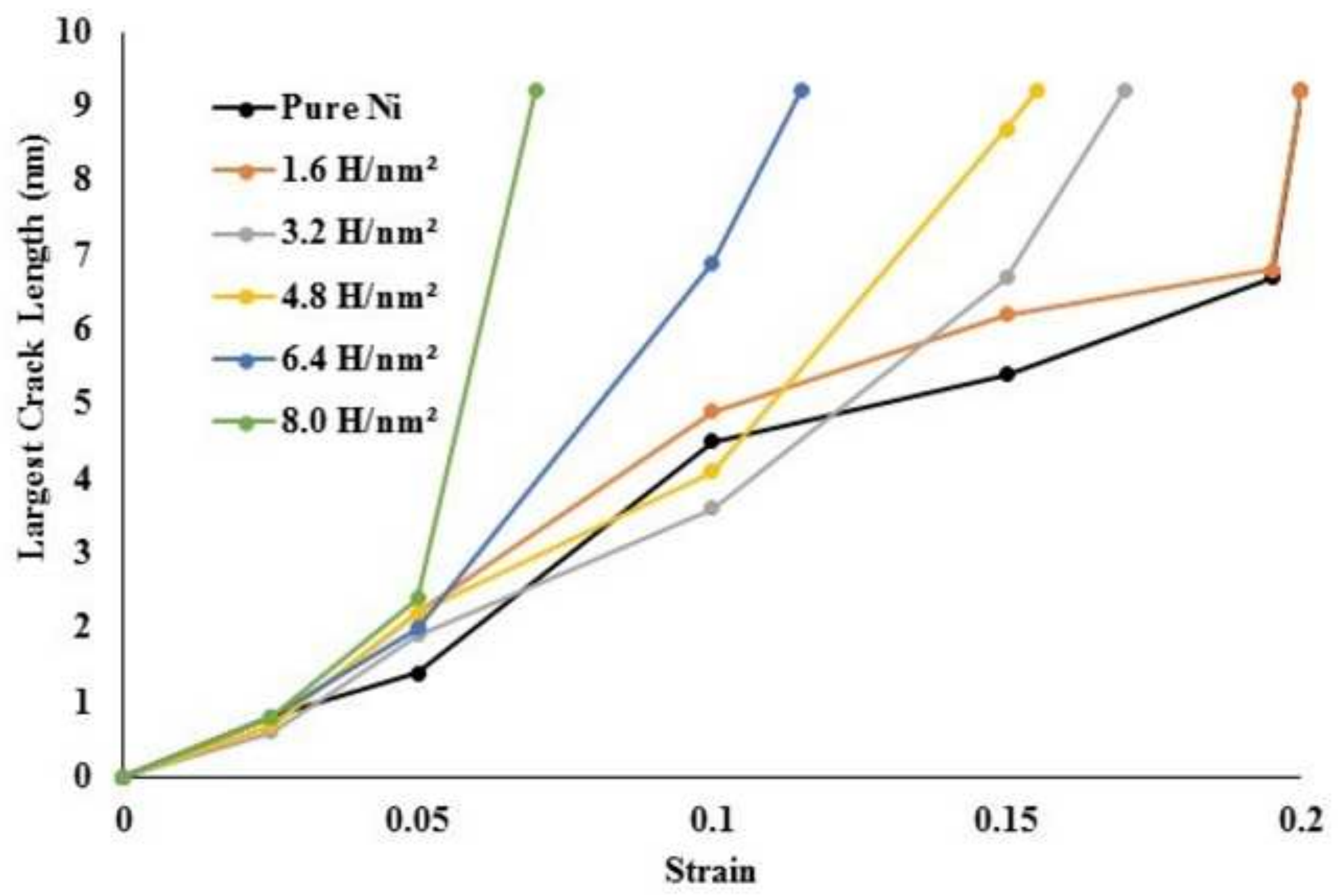

Figure 13: Crack initiation and growth as a function of applied strain for various levels of $\mathrm{H}$ coverage of the grain boundary. 


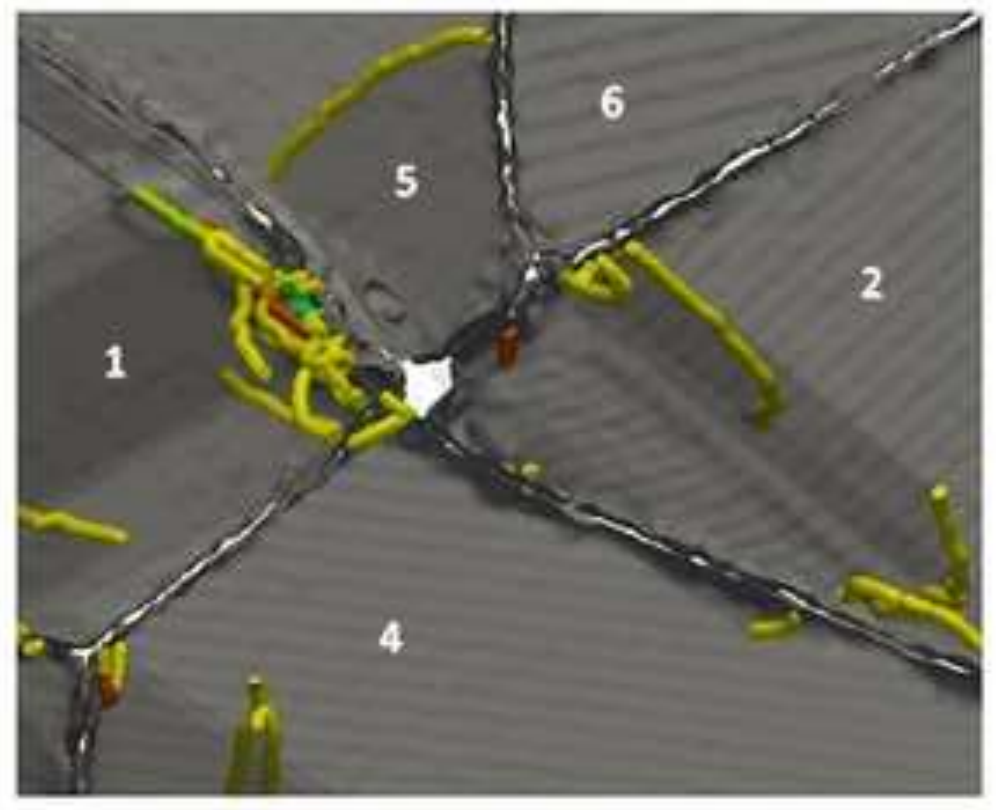

(a)

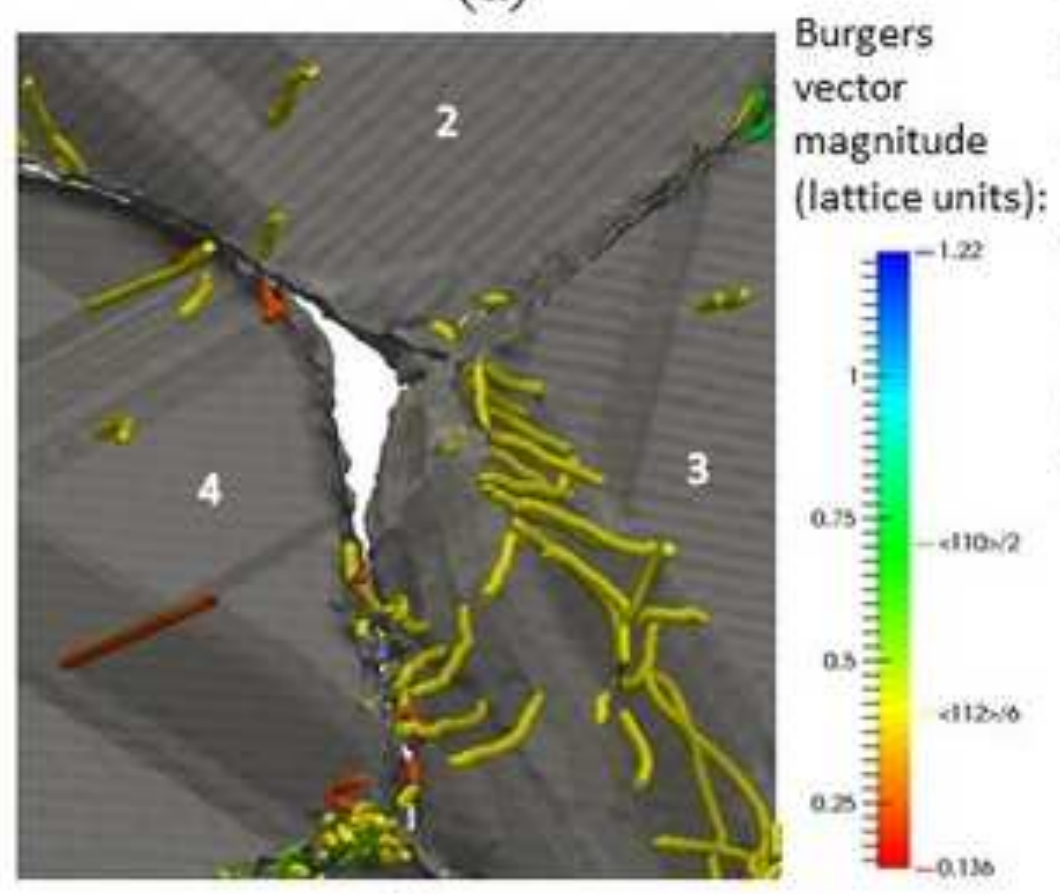

(b)
Figure 14: (a) Dislocation pile ups and crackinitiation observed in $4.8 \mathrm{H} / \mathrm{nm}^{2}$ sample deformed $10 \%$. A crack starts to nucleate near the triple junction of grains 1,2 and 4 . (b) $4.8 \mathrm{H} / \mathrm{nm}^{2}$ sample deformed $15 \%$. A crack nucleates and grows near the triple junction of grains 2, 3 and 4. Dislocations with Burgers vector $1 / 6<112>$ are yellow, $1 / 2<110>$ are green, and $1 / 6<110>$ are red. Darker gray shaded areas are stacking faults. Both cracks appear at sites where dislocations pile up against a boundary. 